\title{
LA CRISIS DE LA DEMOCRACIA REPRESENTATIVA. \\ NUEVAS RELACIONES POLÍTICAS ENTRE DEMOCRACIA, POPULISMO VIRTUAL, PODERES PRIVADOS Y TECNOCRACIA EN LA ERA DE LA PROPAGANDA ELECTORAL COGNITIVA VIRTUAL, EL MICROTARGETING Y EL BIG DATA
}


SUMARIO

1. UNA DEMOCRACIA DE EJERCICIO EXCESIVAMENTE DISCONTÍNUO 2. LOS NUEVOS MEDIOS COMO ESPEJOS DONDE SE REFLEJA LA DEMOCRACIA FORMAL. 2.1 DEMOCRACIA DIRECTA Y DEMOCRACIA REPRESENTATIVA, LA INSUFICIENCIA DE UNA FICCIÓN DESVELADA. 2.2. LOS CIUDADANOS EN UNA DEMOCRACIA AVANZADA DESEAN PARTICIPAR. 2.3. DE UNA SOCIEDAD DE CLASES A UNA SOCIEDAD CLASIFICADA, EL PAPEL DEL BIG DATA, 2.3.1. LOS PERFILES PSICOMÉTRICOS, 2.3.2. LA PROPAGANDA COGNITIVA ELECTORAL Y EL MICROTARGETING. 2.4 PODERES PRIVADOS PODERES PUBLICOS. 3. LAS NUEVAS FORMAS DE COMUNICACIÓN ACARREAN NUEVAS FORMAS DE PARTICIPACIÓN Y CONTROL COMO EL RECALL. 4. LOS PARTIDOS POLÍTICOS HAN DETERIORADO LA CONFIANZA DE LOS CIUDADANOS EN LA DEMOCRACIA. 


\title{
LA CRISIS DE LA DEMOCRACIA REPRESENTATIVA. NUEVAS RELACIONES POLÍTICAS ENTRE DEMOCRACIA, POPULISMO VIRTUAL, PODERES PRIVADOS Y TECNOCRACIA EN LA ERA DE LA PROPAGANDA ELECTORAL COGNITIVA VIRTUAL, EL MICROTARGETING Y EL BIG DATA
}

\author{
LUIS MIGUEL GONZÁLEZ DE LA GARZA \\ Profesor Ayudante Doctor \\ Departamento de Derecho Constitucional \\ UNED

\section{UNA DEMOCRACIA DE EJERCICIO EXCESIVAMENTE DISCONTINUO}

La participación ciudadana activa articulada sobre las tradicionales fórmulas de participación presencial queda excluida prácticamente del circuito de decisión jurídica en los modelos de democracia representativa en los que, una vez cada cuatro años, se ostenta la facultad de seleccionar grupos de candidatos que serán los que verdaderamente desempeñarán la tarea jurídica de tomar decisiones vinculantes para la comunidad a través de la institución parlamentaria. En efecto, si un ciudadano vota una vez cada cuatro años (en unas elecciones generales) estimando la duración de la vida en 80 años (hombres y mujeres) y suponiendo que la edad de votación se inicia a partir de los 18 años de edad, tal ciudadano elector votará en 15 elecciones generales a lo largo de toda su vida — siempre que no opte por la abstención-. Suponiendo una media de 5 minutos por elección (tiempo de reali-

${ }^{1}$ Departamento de Derecho Constitucional. Facultad de Derecho de la Universidad Nacional de Educación a Distancia. Obispo Trejo, 2. 28040 Madrid. Email: lmdelagarza@der.uned.es 
zación de los actos de identificación ante la Mesa electoral y depósito del voto en la urna) dedicaremos en toda nuestra vida 1 hora y 15 minutos a la participación democrática jurídicamente relevante. Algún comentarista señalará que qué sucede con las elecciones municipales, autonómicas y europeas, tendrá razón, la participación asciende, en total, a 5 horas en toda una vida. Si esto es verdaderamente todo el logro de la participación democrática, no existen razones para mostrar satisfacción por tan exiguo triunfo de los modernos estados apellidados «democráticos». Naturalmente, durante esos 300 minutos no se produce ninguna decisión técnicamente vinculante; tan sólo se designa a aquellos a quienes podrán —esos sí- realmente adoptarlas durante el periodo de legislatura.

A consecuencia de la evolución de la democracia liberal-representativa a la democracia de masas en el Estado de partidos, señalaba Gerhard Leibholz ${ }^{2}$ el parlamento pierde su carácter originario y se convierte en el lugar en el que se reúnen los comisionados de los partidos para registrar decisiones tomadas en otros lugares (en las comisiones o en las conferencias de partido) argumento señalado con anterioridad por Heinrich Triepel en el discurso rectoral pronunciado el 3 de agosto de 1927 con ocasión de la celebración del recuerdo del fundador de la Universidad de Berlín ${ }^{3}$, Federico Guillermo III. Como precisaba también M. Duverguer ${ }^{4}$ «los propios parlamentarios están sometidos a una obediencia que los transforma en máquinas de votar guiadas por los dirigentes de partido». Las fracciones se van transformando cada vez más de instituciones del derecho parlamentario en instituciones del Estado de partidos.

Lo anterior es una razón suficiente para que unas sociedades cada vez más interconectadas, sensibles a los problemas y activas políticamente se planteen ensayar fórmulas tentativas que superen ese esquema limitado e insatisfactorio propio de la democracia representativa actual encarnada en la Democracia de Partidos en la que el problema no es la representación sino los Partidos integrados como órganos en el Estado, si no de derecho sí de hecho.

\section{LOS NUEVOS MEDIOS COMO ESPEJOS DONDE SE REFLEJA LA DEMOCRACIA FORMAL}

Las redes sociales y su poder de articulación de nuevas formas de expresión en la dimensión actual deopinión pública política autónoma ${ }^{5}$ son instrumentos aptos tanto para ser el mecanismo que puede explicar la crisis en algunas de sus dimensiones, como para mostrar algunas de sus consecuencias más negativas como es la aparición

${ }^{2}$ Leibholz, Gerhard, «Representación e identidad» en Strukturprobleme der modernen Democratie, Karlsruhe, 1958, págs. 88-111.

3 Triepel, Heinrich, «La Constitución y los partidos políticos», Tecnos, Madrid, 2015, págs. 22-23.

4 Duverguer, Maurice, «Les Patis Politiques», A. Colin, Paris, 1951. pág. 463.

5 Es decir, aquella que no depende de los circuitos profesionales institucionalizados clásicos de generación de opinión pública, tales como la televisión, la prensa escrita o electrónica, ni la radio por radiofrecuencia. 
de nuevos populismos que tienen en las redes sociales un vector de articulación y difusión muy relevante ${ }^{6}$ y cuantificable con los nuevos instrumentos analíticos como el Big Data .

No cabe duda que la democracia de Partidos representativa y, sobre todo, la prohibición del mandato imperativo son actualmente contestados por cada vez más amplios sectores de la ciudadanía que no comparten su justificación teórica. Al existir sistemas de comunicaciones versátiles como Internet que hacen posible, a nivel teórico al menos, hacer presente lo ausente con diversos grados de efectividad que no existían cuando se desarrollaron las justificaciones teóricas tanto de la democracia representativa como de la prohibición del mandato imperativo. Hoy vuelve a ser posible recrear una especie de nuevos: «cabiers de doléances virtuales» de nueva factura, participativos, sujetos a revisión crítica propios de un nuevo estadio o evolución democrática que se forman en muy diversos entornos y sirven a muy diversos propósitos. No existe necesariamente una organización central, se articulan en base a intereses plurales que los desarrollan y se circunscriben, por el momento, a la esfera de la opinión pública política virtual y gozan de propiedades de articulación cada vez más eficientes y mejor cuantificadas, por ejemplo, en el fenómeno cada vez más popular de los «presupuestos participativos de los municipios» como argumenta Olin W right $^{8}$ en el modelo de Porto Alegre, en Brasil.

La suma de los fenómenos micro en los marcos macro revelan una preocupación sensible por la participación «constante» y el «control permanente» de los administrados, de los ciudadanos sobre sus representantes pero ese «control» no se conforma con advertir, señalar y dar publicidad, su significado es cualitativamente distinto. Desea participar activamente, directamente en el marco de una democracia refrendataria o plebiscitaria o, en algunos casos directa lo que entra en colisión con el modelo representativo y la estructura jurídica que lo fundamenta.

La soberanía popular como concepto, como poder, parece encontrar en estas nuevas fórmulas una nueva dimensión al menos en su cuantificación de interés. La democracia representativa como ficción útil y como estructura «institucional» parecería así perder terreno frente a lo existencial.

Como señalara Claus Offe ${ }^{9}$ una institución que funciona alivia a los actores de sus preocupaciones sobre objetivos o estrategias, ya que es posible confiar en que un curso de acción institucionalmente prescrito tendrá efectos beneficiosos o, al menos,

\footnotetext{
${ }^{6}$ Sobre estos aspectos puede verse, González de la Garza, Luis Miguel, «Redes sociales, instrumentos de participación democrática. Análisis de las tecnologías implicadas y nuevas tendencias», Dykinson, Madrid, 2015.

7 Una herramienta como el BIG DATA para investigar las tendencias, por ejemplo, en redes sociales sobre la evolución de las respuestas sociales agregadas a las interacciones de los partidos políticos, permite a estos observar en tiempo real las reacciones por grupos sociales y segmentos de análisis: edades, poblaciones, sectores de afinidad política, riqueza, evolución de la población indecisa a muy diversas cuestiones planteadas por los mismos.

8 Olin Wright, Erik, «Construyendo utopías reales», Akal, Madrid, 2014, págs., 166-177.

9 Offe, Claus «El diseño Institucional en los procesos de transición de Europa del Este», en: Goodin, Robert E, (coomp), «Teoría del diseño Institucional», Gedisa, Barcelona, 2003, págs.251-282.
} 
aceptables para la comunidad. Así, las instituciones permiten que las preocupaciones instrumentales sean reemplazadas por una dosis saludable de ritualismo y conservadurismo. Una vez establecidas y ampliamente consolidadas las instituciones toman vuelo propio debido al invisible funcionamiento del piloto automático. Esto significa que funcionan de manera satisfactoria como un marco supraintencional para la acción apropiada ${ }^{10}$. Ello resulta necesario en los procesos políticos de toma de decisiones colectivas desde que Arrow como recuerda Guy Peters ${ }^{11}$ demostrase que era imposible desarrollar una función social de bienestar de la que se pudiera garantizar que generaría una decisión que satisfaría las prioridades de todos los miembros participantes en una sociedad democrática y totalmente pluralista mediante el método de la preferencia basada en votaciones por mayoría, circunstancia que encuentra precedentes en la obra de Condorcet (1785) problema estudiado un siglo después por C.I. Douglas (1876) y tema de investigación de la literatura moderna sobre elección pública que comienza con Duncan Black (1948) y desarrolla entre otros y como hemos señalado Keneth Arrow ${ }^{12}$. Las instituciones formales e informales ${ }^{13}$ son un medio para eludir en parte este problema fundamental de la acción colectiva y de la democracia directa pura ya que las instituciones proveen de una serie de reglas unánimemente aceptadas o en algunos supuestos implícitamente aceptados que permiten convertir las preferencias en decisiones mediante lo que Robert Aumann describió como «equilibrio correlacionado» ${ }^{14}$. El sistema parlamentario representativo es un claro ejemplo de acuerdo institucional formalmente teorizado de reducción de la complejidad política y social que genera confianza ${ }^{15}$ y seguridad jurídica simultáneamente mediante los procesos públicos de adopción de decisiones jurídicamente vinculantes. Esa es verosímilmente la razón por la que Karl Loewensten viera que la invención de la representación política —una ficción jurídica a la postre como señalara correctamente Kelsen- $-{ }^{16}$ constituye uno de los inventos más significativos de la civilización humana en los últimos tiempos, cuya transcendencia se podría equiparar incluso con la invención del Estado moderno, el

${ }_{10}$ En este tipo de instituciones las relaciones institucionales pueden obedecer a relaciones entre los participantes «blandas» o hasta cierto punto informales o elásticas. Por lo tanto no sería apropiado pensar en modelos de interacción jerárquica estructuradas con rigidez.

11 Peters, Guy B, «El nuevo Institucionalismo. Teoría institucional en ciencia política» Gedisa, Barcelona, 2003, pág 79.

12 Mueller, Dennis C, «Elección pública», Alianza Universidad, Madrid, 1984, pág, 50-51.

13 Para una descripción apropiada de las instituciones informales, puede verse: Gretchen Helmke, y Steven Levitsky, «Informal Institutions and Comparative Politics: A Research Agenda», Perspectives on Politics, Diciembre 2004 | Vol. 2/No. 4, págs. 725-740.

14 Sobre el concepto de «equilibrio correlacionado» puede verse: «Robert Aumann's and Thomas Schelling's Contributions to Game Theory: Analyses of Conflict and Cooperation» Advanced information on the Bank of Sweden Prize in Economics Sciences in Memory of Alfred Nobel, 10 de Octubre de 2005, Sweden, págs. 20-22. http://www.nobelprize.org/nobel_prizes/economic-sciences/laureates/2005/advancedeconomicsciences2005.pdf (09/09/2017).

15 Así lo entendemos con Luhmann, puede verse: Luhmann, Niklas, «Confianza», Anthropos, Barcelona, 1996, págs. 39-52.

16 Kelsen, Hans, «Teoría general del derecho y del Estado», UNAM, México, 1995, Págs.343-344. 
vapor, la electricidad, el motor de explosión o la fuerza atómica. ${ }^{17}$ Al fin y a la postre como remarca muy certeramente Edmund S. Morgan ${ }^{18}$ el mundo político de las simulaciones se mezcla con el mundo real de extrañas maneras, pues el mundo de las simulaciones puede con frecuencia dar forma al mundo real. Para ser viable, para cumplir con su propósito sea cual fuere ese propósito, una ficción debe tener una cierta semejanza con los hechos. Si se apartada demasiado de los hechos la suspensión voluntaria de la incredulidad se desmorona. Y, a la inversa, podría desmoronarse si los hechos se alejan demasiado de la ilusión a la que queremos que se parezcan. No es desconcertante es la naturaleza lógica de la sociedad (conceptual, proposicional) como argumenta convincentemente John Searle ${ }^{19}$. Los hechos en el sistema representativo se han separado demasiado de la realidad pensada por los ciudadanos y la ilusión del sistema ha empezado a erosionarse.

\subsection{Democracia directa y democracia representativa, la insuficiencia de una ficción desvelada}

Los modelos basados en la democracia directa que en la actualidad se propugnan por ciertas sensibilidades, en muchas ocasiones ignorantes de su estructura histórica y basada únicamente en un pensamiento romántico elemental por primitivo y por ello meramente reaccionario, van en contra del sistema institucional representativo ${ }^{20}$ que es un avance por completo necesario y, por lo tanto, generan una complejidad en las sociedades avanzadas modernas que estimamos sencillamente inmanejable en diversas dimensiones cruciales del funcionamiento democrático de las instituciones. Y cuya evolución o involución más bien podría poner en grave peligro los logros alcanzados en las modernas democracias constitucionales. No podemos desconocer

${ }^{17}$ Loewenstein, Karl, «Teoría de la Constitución» 2. ${ }^{a}$ Ed, trad. de Alfredo Gallego Anabitarte, Ariel, Barcelona, 1976, pág. 70.

18 Morgan, Edmund S, «La invención del Pueblo. El surgimiento de la Soberanía popular en Inglaterra y los Estados Unidos», Siglo veintiuno editores, Argentina, 2006, págs. 13-16.

19 Searle, John, «Creando el mundo social. La estructura de la civilización humana», Paidós, México, 2014.

${ }^{20}$ La representación como concepto es un fenómeno complejo. Si bien, compartimos la idea con Santiago Ramón y Cajal de que: «no hay cuestiones agotadas sino bombres agotados en las cuestiones»; ésta es la impresión que se puede extraer del estudio de este problema. Las investigaciones, o la exposición de algunos resultados, como los desarrollados por Böckenforde en relación con el concepto norteamericano de representación — responsiveness- (receptividad, significa una sensibilidad y una disposición por parte de los representantes a asumir los deseos e intereses de los representados, unidas ambas a la correspondiente capacidad de percibirla) y el alemán, matizado de Hegel (según el cual la representación presupone la existencia de una relación extrajurídica específica, que se funda y se manifiesta en la confianza), confirman los mejores intentos por encontrar o hallar un término intermedio y aceptado entre las posiciones extremas de la representación formal de mandato libre y la posición del mandatario vinculado a instrucciones, aún no hallado sin recurrir a construcciones sumamente abstractas y que deben ser objeto de investigaciones ulteriores, que sería nuestro deseo abordar y que no podemos proseguir aquí. Ernst Wolfgang Böckenforde, Estudios sobre el Estado de Derecho y la Democracia, Trotta, 2000, pág. 150.

N.o 103, septiembre-diciembre 2018, págs 257-302 
con Sartori ${ }^{21}$ que una democracia pura (que no sea ni liberal ni constitucional) puede perfectamente volverse absoluta: la hipótesis de un «absolutismo democrático» es perfectamente plausible, nada lo impide en los nuevos nacionalismos populistas como el catalán en España. Ahora bien, ello no quiere decir que estos modelos no sean aprovechables y realmente útiles para reacondicionar, perfeccionar o proponer líneas evolutivas del modelo representativo o «demorepresentativo» a nuevas sensibilidades y exigencias de participación activa y control de la sociedad moderna mediante los instrumentos que la tecnología está ensayando en nuestras sociedades tecnológicas.

En efecto no hay razones técnicas por las que no ensayar avances en la estructura electoral, por ejemplo, por la que se diseñen nuevos circuitos electorales en los que el «Diputado de Distrito» pueda ser revocado y suplido por reservas mediante determinados números de votos de revocación. Someterse a un control más intenso por parte de sus electores mediante fórmulas basadas en redes sociales de accountability más precisas y eficientes, sometiendo a un escrutinio público la actividad del representante y pudiendo exigir responsabilidad jurídica a su acción política para la que quizá ya no existe una justificación de que no sea únicamente la responsabilidad política la exclusivamente exigible tras la finalización o expiración de su periodo temporal de mandato, mediante la ineficiente como tardía retirada de la confianza para un nuevo periodo o mandato electoral cuatrienal.

Otras razones pueden ser ponderadas, desde el momento en que las tecnologías hacen posible redefinir las figuras jurídicas que otrora fueron congruentes con momentos históricos dados y facultades técnicas disponibles que hoy han sido claramente superadas. Entre ellas, la posibilidad de renunciar por el elector al secreto del voto en determinadas circunscripciones y con determinadas finalidades, como por ejemplo la local. Lo que tendría dos efectos de gran interés científico que ya fueron advertidos por Montesquieu: guía de la elección de los notables, si es que hoy fuese posible encontrarlos o por Robespierre como medio de desarrollar un valor cívico. Pero en el ámbito que nos ocupa el voto «no secreto» puede tener dos significados distintos, por una parte, hacer el voto electrónico remoto posible ya que el elector puede asegurarse de que nadie ha modificado el signo de su voluntad ${ }^{22} \mathrm{y}$, en segundo lugar, que esa ausencia de secreto transforma la responsabilidad asociada del sufragio. Acontece que el voto secreto desliga al votante del representante. El voto no secreto — que no necesariamente quiere decir público, sino sujeto a publicidad restringida dependiente de la voluntad del votante- genera responsabilidad al establecer una relación univoca representante-representado genuinamente democrática. ${ }^{23}$ No se debe

21 Sartori, Giovanni, "¿Qué es la democracia», Taurus, Madrid, 2007, pág. 146.

22 Ello unido a técnicas de firma electrónica que acrediten el principio de personalidad del voto, sólo así es posible emplear el voto electrónico por Internet.

${ }^{23}$ Algunas reflexiones sobre el secreto del voto, pueden verse en: Barrat i Steve, Jordi, «El secreto del voto a debate», en "Constitución y democracia: Ayer y hoy», Libro homenaje a Antonio Torres del Moral, Universitas, Madrid, 2012, Vol., II, págs.1881-1892. 
perder de vista que como recordara atinadamente Carl Schmitt ${ }^{24}$ el método del sufragio secreto no es democrático sino expresión del individualismo liberal, así como también su promotor en el siglo Xix Jeremías Bentham fue un liberal típico. En efecto, la aplicación consecuente de la votación secreta transforma al ciudadano, es decir, a la figura específicamente democrática — política — en un hombre o mujer privados, que desde la esfera de lo privado — ya sea en sus intereses económicos, religiosos o ambos - manifiesta una opinión privada y emite su voto. El sufragio secreto significa que el ciudadano que vota se encuentra aislado en el momento decisivo. De esa manera se hace imposible la asamblea del pueblo presente y toda especie de aclamación, quedando por completo rota la vinculación entre el pueblo reunido y la votación. El pueblo ya no elige y vota como pueblo.

Los métodos de la actual elección popular y de la actual votación popular en la moderna Democracia no contiene en modo alguno el procedimiento de una verdadera elección popular o verdadera votación popular sino que organizan un procedimiento de votación individual con adición o suma de votos. El hecho de la aplicación consecuente - precisa Schmitt - del sufragio secreto, no es democrático porque expulsa al ciudadano individual de la esfera de lo público y lo convierte en hombre privado. Lo anterior es tanto más chocante cuanto que, según la concepción democrática el ciudadano que vota no es un particular, sino que realiza una función pública específicamente en el sistema representativo. Hay que precisar que no modifica esa funcionalización —advertida por Schmitt - el hecho de que para el ciudadano se trate de un derecho público subjetivo ya que desde la perspectiva del Estado, que es aquí la que nos interesa, la construcción de la voluntad jurídica del mismo no puede verse sino como una función propia del proceso electoral en su dimensión de garantía institucional que es en la que el elector se integra como advirtiera correctamente León Duguit ${ }^{25}$.

Pero según la regulación actual de los métodos del sufragio secreto, se transforma en un particular precisamente en el momento decisivo de emisión del sufragio. El secreto del sufragio es concretamente el punto arquimédico en el que se produce la transformación, la inflexión podríamos decir y tiene lugar la desviación de la democracia hacia la protección liberal del particular. No le faltaba razón a Schmitt cuando señalaba que quizás se encuentra ahí uno de los arcana de la Democracia burguesa. Si bien y como señalara agudamente Duverguer esto no sería sino la consecuencia natural de la teoría del mandato representativo y de sus presupuestos ontológicos entre los cuales se encontraba proteger los intereses de la burguesía mediante la creación de una oligarquía de representantes. ${ }^{26}$ En opinión de Presno Linera ${ }^{27}$ naturalmente bajo el sistema representativo que aquí consideramos, en un sistema democrático la posibilidad de que los individuos puedan intervenir

${ }^{24}$ Schmitt, Carl «Teoría de la Constitución», Alianza Universidad, Madrid, 1982, pág. 239.

25 Duguit, Leon, «Traite de Droit Constitutionnel» (2a y 3a edición, Paris, Edit. De Brocard Sue, 5 vol., 1928, reedición actual de Cujas), Tomo II, págs.585-589.

26 Duverguer, Maurice, «Instituciones políticas y derecho constitucional», Ariel, Barcelona, 1970, págs.119-123.

${ }_{27}$ Presno Linera, Miguel Ángel, «El derecho de voto», Tecnos, Madrid, 1991, pág. 106. 
en el ejercicio del poder no desempeña una mera función de legitimación, sino que sirve para canalizar el flujo de expectativas políticas de la sociedad al Estado, con lo que la comunidad se autodetermina de manera constante y puede decidir el sentido de su orientación política. Autodeterminación que presupone, como advierte Martin Kriele, la dignidad humana de actitud derecha, sin miedo ${ }^{28}$. Lo anterior sería cierto si los partidos políticos recogiesen de la sociedad el flujo de expectativas que señala el profesor Presno, lo cierto, sin embargo, es que la realidad es por completo distinta, no existe — - en líneas generales - tal canalización y los partidos políticos viven de espaldas en muchas ocasiones a la sociedad de la que únicamente y en los periodos electorales de actividad proponen a esa sociedad mediante sus programas electorales paquetes de opciones programáticas (el ficticio contrato con los ciudadanos) carentes por completo de exigibilidad jurídica que constituyen la supuesta contraprestación por recibir la legitimación de los electores en el acto de votación que es un acto meramente técnico de designación de representantes como precisara agudamente Loewenstein. ${ }^{29}$ Una vez que la elección se ha verificado prosigue la vida autorreferencial de los partidos con un autismo por lo común de elevada intensidad con respecto a la sociedad y quedando el soft control de su actividad política en manos principalmente de los medios de comunicación de masas, los cuales cada vez pertenecen de forma más acentuada a grupos económico-políticos nacionales e internacionales — poderes privados en suma - que orbitan en las proximidades de los partidos políticos con perturbadores efectos gravitatorios como argumenta Stephen Holmes ${ }^{30}$ sobre la función ortodoxa de informar verazmente como canon de ajuste a los hechos noticiable de los medios de masas, si bien y como advirtiera Niklas Luhman ${ }^{31}$ la sospecha de la manipulación de la realidad por estos es patente ${ }^{32}$.

${ }^{28}$ Pues quien movido por el miedo debe inclinar la espalda ante el gobernante, no es él mismo, obviamente, un gobernante, señala Kriele, quizá un elemento escasamente estudiado en nuestra transición ha sido el miedo que tras 40 años de franquismo permeaba aún la sociedad de la transición. Kriele, Martin, «Introducción a la Teoría del Estado. Fundamentos históricos de la legitimidad del Estado constitucional democrático», Depalma, Buenos Aires, 1980, pág. 315.

29 Así lo señala el autor: «Las elecciones sirven, en primer lugar, para que el electorado designe a los detentadores del poder en el gobierno y en el parlamento,», Loewenstein, Karl, «Teoría de la Constitución», Ariel, Madrid, 1979, pág. 326.

30 Holmes Stephen, «¿Restricciones liberales al poder privado?: Reflexiones sobre los orígenes y las justificaciones de la regulación del acceso a los medios de comunicación», Isonomia, n. ${ }^{\circ}$ 26, Abril, 2007, pág. 7-48.

31 El éxito social de los medios de masas se basa en que imponen la aceptación de los temas. Esto, que argumenta Luhmann, es totalmente independiente de que se tome partido positivo o negativo sobre la información, sobre las propuestas de sentido o sobre los valores ya conocidos. Agrega el autor: por consiguiente, el sistema, siempre hará referencia a un estado de información propio, a lo que él considera novedad y sorpresa, para conferirle un valor de información. Se entiende, entonces, que se despierte la sospecha de que los medios de comunicación manipulan la realidad.

Luhmann, Niklas, "La realidad de los medios de masas», Ed. Anthropos, 2000, pág. 18.

32 Podemos advertir esta sospecha en la selección de la agenda informativa por ejemplo en medios como la televisión en la cual todas las cadenas informativas «replican las informaciones» con mínimas diferencias que lo son más bien de tiempo que de contenido. 


\subsection{Los ciudadanos en una democracia avanzada desean participar}

Debemos recordar en el marco de la democracia directa griega de los siglos IV y v, A.C, la cual es un referente inexcusable de balances no igualada, que ésta disponía de mecanismos cuya finalidad era precisamente evitar la corrupción como recuerda Bernard Manin o Sinclair. Así la democracia Ateniense confiaba a ciudadanos seleccionados por sorteo $^{33}$ — una forma especialmente justa de seleccionar la idoneidad neutral entre iguales por medio del azar ${ }^{34}$ - la mayor parte de las funciones no desarrolladas por la asamblea popular, la ekklesia. Tales magistraturas asignadas por sorteo eran habitualmente colegiadas —otra fórmula de control- El mandato en el cargo era de un año y no se permitía que los ciudadanos ocupasen una magistratura más de una vez y aunque podían ser nombrados para una serie de magistraturas diferentes a lo largo de su vida, el calendario para rendir cuentas (no se podía acceder a un nuevo cargo sin haber rendido cuentas del anterior) suponía, que en la práctica, ninguna persona podía ejercer de magistrado por dos años consecutivos. Todos los ciudadanos con 30 años cumplidos y que no estuvieran bajo pena de atimia (privación de los derechos civiles) podían acceder a una magistratura. Sin embargo aquellos cuyos nombres habían sido extraídos por sorteo debían someterse a una investigación dokimasia antes de poder ocupar el cargo. En la investigación se examinaba si estaban legalmente cualificados para ser magistrados; y también se comprobaba que el comportamiento con sus padres había sido satisfactorio, si habían pagado sus impuestos y si habían realizado el servicio militar. También existían cargos electivos, recordemos el caso de Pericles que fue elegido como general stratego durante más de 20 años o el más famoso de los generales griegos durante el siglo v, Foción que lo estuvo por más de 45. Los atenienses como precisa Sinclair reservaban la designación por elección para las magistraturas en las cuales la

33 En el caso de los magistrados sólo eran introducidos en la máquina de la lotería, kleroteria, los nombres de los que querían ser tenidos en cuenta, es decir, entre los que se ofrecían como candidatos.

34 El sorteo es, posiblemente, la fórmula idónea para solucionar el problema de selección entre iguales más justa, así, por ejemplo, en el caso EE.UU. contra Holmes, el problema era a quién se tendría que haber arrojado por la borda de un bote salvavidas apiñado y deteriorado. La tripulación había arrojado a catorce pasajeros varones por la borda, pero el juez declaró que las víctimas se tendrían que haber escogido por suertes entre todos ellos, tripulantes y pasajeros. La suerte, manifestó, es «el modo más justo y, de alguna manera, una apelación a Dios, para seleccionar la víctima... De ninguna otra manera quienes poseen derechos iguales se encuentran en igualdad de condiciones, y de ninguna otra manera es posible resguardarse de la parcialidad y la opresión». Para un análisis detallado y extenso del sorteo desde diversas perspectivas políticas (históricas y contemporáneas) y óptimas puede consultarse la monografía de Elster, Jon «Juicios Salomónicos (las limitaciones de la racionalidad como principio de decisión)», Gedisa, Barcelona, 1999. En concreto el capítulo 2, págs. 40-107. 
competencia $^{35}$ — como capacidad — se juzgaba vital, tales como los generales y altos cargos administrativos militares a partir del siglo $\mathrm{V}$ y los principales cargos financieros $^{36}$. Como hemos querido caracterizar en estas brevísimas pinceladas, dos ideas dejamos señaladas, la competencia y la capacidad eran buscadas por el entramado institucional de la democracia griega intentando también controlar las fuentes de corrupción.

Como advirtiera Carré de $\mathrm{Malberg}^{37}$ lo que caracteriza al régimen representativo es que en él, el pueblo no tiene la potestad de decidir. El cuerpo electoral es desde luego órgano de creación del Parlamento, pero no órgano de volición; más aún — prosigue Carré- el fin mismo del régimen llamado representativo es excluir sistemáticamente al pueblo de la potestad de querer o sea de decidir por el Estado y reservarla únicamente a los representantes. Así pues, en la democracia representativa todos los esfuerzos que pudieran intentarse para que el cuerpo de ciudadanos activos fuese considerado como un órgano primario de voluntad estatal fracasarán ante la infranqueable objeción de que aquí el pueblo se limita a nombrar el órgano encargado de querer. La diferencia jurídica capital que separa estas dos clases de democracia (la directa o pura y la representativa) es que en la democracia pura los elegidos de los ciudadanos (representantes etimológicamente considerados o la única fórmula de representación que Rousseau ${ }^{38}$ consideraba posible) han de expresar la voluntad de estos y, por este motivo, sus decisiones quedan subordinadas bien sea en cuanto a la iniciativa, bien sea en cuanto

35 Así parece demostrarlo los antecedentes de los que disponemos, siguiendo en este punto a $\mathrm{R}$. K. Sinclair: La Asamblea podía disfrutar con un orador divertido y hasta podía rechazar los consejos de sus dirigentes — tal como asegura Plutarco que se hacía-, pero cuando se trataba de tomar decisiones cruciales como nombrar a los estrategos, los atenienses invitaban a hablar a los ciudadanos más serios y más sensatos [...]. Y es evidente que la Asamblea, especialmente en el siglo IV, no admitía consejo sin examinarlo, ni toleraba a mentecatos e incompetentes. Es cierto que Platón hace que Sócrates distinga entre cuestiones técnicas, tales como la construcción de barcos, en el que se pedía el consejo de un experto, y cuestiones políticas en las que los atenienses podrían escuchar el parecer de cualquiera. En asuntos técnicos, todo aquel que no demostrase ser un experto, aunque fuera un noble rico y de buena cuna, era según Platón insultado y abucheado hasta que se retiraba o se le retiraba de la tribuna. Indudablemente, añadimos a las palabras anteriores, el hecho de que nuestras sociedades técnicas sean mucho más complejas, exigiría la adopción de estrategias jurídicas que garantizasen, obviamente con carácter constitucional, que la cultura sea junto con la isegoria los dos cánones determinantes de la expresión política del demos. K. Sinclair, Democracia y participación en Atenas, Alianza Editorial, Madrid, 1999, pág. 69-70.

36 Manin, Bernard, «Los principios del gobierno representativo», Alianza, Madrid, 1998, págs. 24-26.

37 Raymond Carré de Malberg, Teoría General del Estado, FCE, México, 1998, págs. 872-1097.

38 Hay que recordar, no obstante, que el mismo Sieyes señalará: «Pero subrayemos, porque ésta suerte de precisiones deben estar siempre presentes para una cabal comprensión del tema, que la misión dada a los representantes no puede implicar jamás una alienación. Esta misión es esencialmente libre, en efecto, pero constantemente revocable y limitada, a voluntad de los comitentes, tanto por lo que se refiere al tiempo, cuanto a la naturaleza de asuntos a tratar». Enmanuel J. Sieyes, Ideas sobre los medios de actuación que podrán disponer los representantes de Francia en 1789. (primera sección), en: El Tercer Estado y otros escritos de 1789, Austral, Madrid, 1991, pág. 51. (insiste Sieyes, con los mismos argumentos que se repiten en la sección tercera de la misma obra, pág. 92). 
a la perfección de la decisión a una voluntad preponderante que es la de la asamblea del pueblo.

En la democracia representativa el cuerpo de los elegidos no representa una voluntad anterior ni sus decisiones dependen de una voluntad que domine la suya, sino que crea él mismo la voluntad de la nación (del Estado como personificación jurídica de este) por la que está encargado de querer. Y precisamente en esto es un órgano de la nación. Pues —importa observarlo (recuerda el autor)— en realidad únicamente en el caso de la democracia pura es cuando se produce una representación en el sentido ordinario de la palabra.

Carré de Malberg insiste en el estudio del régimen parlamentario, como corrección del sistema representativo, en que es verdad que incluso en el sistema parlamentario los electores no pueden imponer un programa obligatorio a sus elegidos en el momento de la elección, ni pedirles cuentas jurídicamente de sus actos en el transcurso o al finalizar la legislatura. Tal como lo entendían Sieyès y Barère, los ciudadanos en el sistema representativo no tienen ninguna participación en la potestad legislativa. La oposición pues entre régimen representativo y democracia consiste esencialmente en que en ésta el ciudadano es legislador y en aquella sólo es elector. Esta es la razón por la que Hans Kelsen ${ }^{39}$ señalaba que desde el momento que las constituciones modernas prohíben expresamente toda vinculación formal del diputado a las instrucciones de sus electores y hacen jurídicamente independientes las resoluciones del parlamento de la voluntad del pueblo, pierde todo fundamento positivo la afirmación de que la voluntad del parlamento es la voluntad del pueblo y se convierte en una pura ficción (inconciliable con la realidad jurídica). La ficción —continúa Kelsen — presta aquí un eminente servicio de servir de freno al proceso ilimitado de la evolución democrática, la cual encuentra su comienzo y su fin, al mismo tiempo, en la introducción del parlamentarismo.

En efecto, se trata de una ficción de aquellas descritas por Hans Vaihinger ${ }^{40}$ y su Filosofía del «como sì» ${ }^{41}$ junto con la pregunta que el filósofo se formulaba: ¿Cómo es posible que lleguemos con ideas falsas a resultados acertados? Si bien, las ideas que podrían aquí considerarse falsas, no necesariamente lo son como advirtiera Lon F. Fuller ${ }^{42}$ sino que representan más bien una desviación técnica interesada de la idea democrática desconocida por una mayoría de la sociedad no experta, como precisara

39 Hans Kelsen, Teoría General del Estado, Comares, 2002, págs. 509-517.

40 Vaihinger, Hans, «The Philosophy of "As if» A System of the Theortetical, Practical and Religious Fictions of Mankind», Routledge \& Kegan Paul Ltd, London, 1924, págs., 200-215.

41 Trabajos posteriores de su escuela, fueron los de Rolf Mallachow, así como la obra de Walter Strauch para el que todo el Derecho no es otra cosa que una ficción. Es aquí también relevante la obra de Josef Esser «Deutsches Recht», de 1941, obra en la que Esser distingue varios tipos de ficciones jurídicas.

42 Señalaba Fuller que las ficciones son, hasta cierto punto, simplemente las expansiones forzosas del lenguaje del derecho, Lon L Fuller, en: Kelsen Hans, Lon F. Fuller, Alf Ross, «Ficciones jurídicas», Fontamara, Mexico, 2006, pág. 77. 
Jellinek $^{43}$ que advierte las insuficiencias del modelo primigenio con relación a otro modelo evolutivo posterior del que reivindican facultades de control y responsabilidad que el sistema representativo no satisface en un momento histórico en el que los ciudadanos son conscientes de esas insuficiencias y de lo insatisfactorio del modelo vigente en un nuevo marco o entorno de participación política deseada propia del siglo XXI.

Lo anterior, a nuestro juicio correcto debe no obstante equilibrarse o ponderarse con los conocimientos que las ciencias sociales nos han proporcionado en los últimos 50 años sobre lo que de cierto hay en conceptos abstractos y en muchas ocasiones ideales como voluntad general u opinión pública. Sería tedioso e infructuoso revisar la extraordinariamente amplia literatura que sobre los tópicos señalados viene produciéndose desde entonces. A nuestro juicio creemos esencialmente correctas y suficientes las aportaciones realizadas por Josef Schumpeter en el capítulo XXI de su célebre ensayo Capitalismo, socialismo y democracia ${ }^{44}$ y que recientemente Simone ${ }^{45}$ sintetiza precisando el impresionante análisis de los límites, las distorsiones y las insuficiencias que hacen insensatos los conceptos de voluntad general y de opinión pública. Schumpeter, en efecto, no reconoce al público idea alguna del bien común, sostiene en el ensayo que «el ciudadano típico se hunde a un nivel inferior de rendimiento mental apenas entra en el campo político. Discute y analiza de un modo que dentro de la esfera de sus intereses reales él mismo reconocería fácilmente como infantil. Vuelve a ser un primitivo. Su pensamiento se convierte en asociativo y afectivo» lo que es congruente con la racionalidad limitada ${ }^{46}$ del ser humano como advirtiera Herbert A. Simon. En consecuencia su voluntad no madura por la fuerza de opiniones racionales sino que es «una mezcla indeterminada de impulsos vagos, que operan sobre eslóganes recibidos y sobre impresiones erróneas». Para activar esa mezcla basta un hecho imprevisto, la imaginación que se pone en funcionamiento, el prejuicio ideológico o personal — circunstancia señalada también por Karl Popper- ${ }^{47}$ el despecho o el favor, el efecto seductor o

43 Jellinek, George, «Teoría General del Estado», FCE, México, 2000, pág., 507.

44 Schumpeter, J.A, «Capitalismo, Socialismoy Democracia», Tomo II, Folio, Barcelona, 1996, págs.321-342.

45 Simone, Raffaele, «El hada democrática. Cómo la democracia fracasa», Taurus, Barcelona, 2015, pág. 94.

46 Como señalan Simon y buena parte de la escuela económica neoinstitucional que aceptan tal premisa: «Como criaturas de racionalidad limitada incapaces de habérnoslas con el mundo en toda su complejidad, nos formamos una imagen simplificada del mismo y lo vemos desde nuestro punto de vista organizacional particular, esto es, desde los intereses y objetivos de nuestra organización». H. A Simon, «Las ciencias de lo artificial», Comares, Granada, 2006, pág. 52. En idéntico sentido. O. E. Williamson, «Las instituciones económicas del capitalismo», FCE, México, 1989, pág. 10.

${ }^{4}$ No cabe ninguna duda — señala el autor- de que todos somos víctimas de nuestro propio sistema de prejuicios; de que todos consideramos muchas cosas evidentes por sí mismas; de que las aceptamos sin espíritu crítico e incluso con la convicción ingenua y arrogante de que la crítica es completamente superflua; y, desgraciadamente, los hombres de ciencia no hacen excepción a la regla, aun cuando hayan logrado librarse superficialmente de algunos de sus prejuicios en el terreno particular de sus estudios. K. R. Popper, «La sociedad abierta y sus enemigos», Paidos. Barcelona, 1957, pág. 385. 
repulsivo de una persona o que un grupo pueden inspirar. Podemos reconocer en lo anterior como los modelos de democracia asamblearia informal, recrean algunos de los nefastos efectos señalados por Schumpeter y que se han experimentado, por ejemplo, en España en fenómenos políticos asociativos de escasa articulación como el 15M que se han consolidado a través de las redes sociales posteriormente y de los que han surgido partidos políticos como Podemos. Cuando Herbert A. Simon habla de la racionalidad limitada de las personas, el argumento tiene precedentes entre los cuales destaca, precisamente por su claridad el de John Locke en el ensayo sobre el entendimiento humano singularmente en el Capítulo XX del Libro $I^{48}$.

Esos hombres a los que se refiere Locke, quizá son aquellos a los que hacía mención Abraham Lincoln como más adelante veremos, a los que se les puede engañar siempre y que precisan por ello mecanismos institucionales eficientes para que no sean víctimas como señala Susan C. Stokes de la manipulación sistemática de las creencias causales y, por tanto, de las preferencias inducidas lo que constituye una patología potencial del proceso democrático que debe tomarse muy enserio en los debates sobre la deliberación virtual ${ }^{49}$ y que es, precisamente, el populismo más descarnado impulsado por líderes elocuentes ${ }^{50}$ y demagogos que son quienes efectúan ésa manipulación sobre la credulidad y racionalidad limitada de las personas, como advirtiera Bertrand Russell ${ }^{51}$ y que precisan por ello

${ }^{4} \mathrm{Al}$ recordar, que hay hombres de un silogismo, otros de sólo dos silogismos, y eso es todo, y otros que pueden dar un paso más. Gente como ésa no es capaz de discernir de qué lado están las pruebas más convincentes; no pueden seguir con constancia la opinión que en sí misma sea la más probable. Ahora bien, que en efecto existan semejantes diferencias entre los hombres, por lo que toca al entendimiento, es algo que nadie que haya sostenido conversación con sus vecinos podrá poner en duda, aun cuando no haya tenido ocasión de frecuentar, por una parte, los tribunales de Westminster-Hall y la bolsa de valores, o, por la otra parte, los hospitales y los manicomios. Si semejante diferencia en el intelecto de los hombres procede de algún defecto de los órganos del cuerpo particularmente adaptados para pensar, o si procede del embotamiento e indocilidad de esas facultades por falta de uso; o, como algunos piensan, de la diferencia natural de las almas mismas de los hombres; o de alguna de esas causas, o de todas juntas. Una cosa sólo es evidente: que existe, en efecto, una diferencia de grado en el entendimiento, en la aprehensión y en el raciocinio de los hombres, y que esa diferencia es tan grande que se puede afirmar, sin calumniar al género humano, que hay una mayor distancia a este respecto entre algunos hombres y otros, que entre algunos hombres y ciertas bestias. Locke, John, «Ensayo sobre el entendimiento humano», FCE, México, 1994, pág. 716.

49 Stokes, Susan C, «Patologías de la deliberación» en: Jon Elster (comp), «La democracia deliberativa», Gedisa, Barcelona, 2001, págs. 161-181.

50 Señalaba con acierto Hobbes: «El oficio de la elocuencia consiste en hacer que parezca lo malo, bueno; lo perjudicial, útil; lo deshonesto, honesto, y es verdaderamente importante lograr que pase por justo aquello que no lo es, siempre y cuando que el orador estime que esto sirve a su intervención. Es lo que llamamos persuadir. En realidad aunque el orador dé la impresión de querer razonar, no lo hace más que a medias, y la mayoría de sus razonamientos, poco sólidos, están fundados sobre principios falsos, que sólo tienen una cierta apariencia de verdad y en opiniones vulgares, casi todas falsas». Thomas Hobbes, Del Ciudadano, Tecnos, Madrid, 1996, pág. 20.

51 Russell, Bertrand, «Pensamiento libre y propaganda oficial», en «Viaje a la Revolución», Ariel, Madrid, 2017, pág. 186.

N.o 103, septiembre-diciembre 2018, págs 257-302 
protección $^{52}$. Hoy por fortuna disponemos de algunos conocimientos científicos relevantes de cómo identificar esas conductas, pero no de crear aún medios jurídicos idóneos para neutralizarlas. Acontece singularmente así con la teoría de sesgos de Daniel Kahneman ${ }^{53}$ la cual ha contribuido significativamente e ello ${ }^{54}$ y contribuirá mucho más en el futuro creando algunas bases idóneas para regulaciones consistentes con sus hallazgos que tengan en cuenta las fórmulas de persuasión basadas en la forma de procesamiento de la información del cerebro humano y quizá puedan ser estas, en alguna medida, restringidas jurídicamente como sugiere Cass $\mathrm{R}$. Sunstein ${ }^{55}$ de modo equivalente o análogo a como protege nuestra actual Constitución contra la mentira a través del canon de la veracidad en lo que respecta a la información. Sin embargo las noticias falsas o las mentiras, por ejemplo, como han estudiado Soroush Vosoughi, Deb Roy y Sinan $A_{r a l}^{56}$ entre otros, se difunden con mucha más amplitud y rapidez en las redes sociales como Twitter que la verdad, singularmente si son rumores políticos.

\subsection{De una sociedad de clases a una sociedad clasificada, el papel del big data}

En nuestras modernas sociedades en red según la expresión de Manuel Castells ${ }^{57}$ se han producido dos fenómenos diversos pero que actúan sinérgicamente. Por una parte, la disposición de las tecnologías precisas para procesar e interpretar inmensas cantidades de datos y, por otro, una simétrica erosión de la privacidad acentuada por el miedo derivado de los atentados terroristas producidos en los Estados Unidos del año 2001, veamos ambos femémonos muy brevemente.

Hoy los poderes públicos pero también los privados tienen a su disposición un instrumental técnico que ni en sus más exorbitantes sueños de control de los ciudadanos hubiesen podido imaginar los gobiernos más totalitarios de la historia de la humanidad. Saber qué hacen, cómo piensan o cuáles son los deseos de los ciudadanos. Penetrar en sus reductos de intimidad y averiguar «casi» todo sobre ellos es hoy posible sin el empleo de métodos coercitivos de obtener confesiones conductuales y orales, sino a través de refinados análisis de sus datos de tráfico (metadatos) ${ }^{58}$

52 En el circuito de la información tenemos un ejemplo de esta protección cuando la Constitución prevé una salvaguarda de esa naturaleza para la sociedad en su conjunto en la letra d) del número 1 del artículo 20 de la CE, en efecto, se constitucionalizada el canon de la veracidad en la comunicación o recepción libre de información a través de cualquier medio de difusión. Se protege a la colectividad contra la mentira.

53 Kahneman, Daniel, «Pensar rápido, Pensar despacio», Debate, Barcelona,2012.

54 Por ejemplo en la aplicación de estos conocimientos científicos en ramas del saber cómo la «economía conductual» que está revolucionando los aspectos sobre el comportamiento humano en la economía.

55 Sunstein, Cass R, «(más) Simple. El futuro del Gobierno», Marcial Pons, Madrid, 2014, págs. 145-160.

56 Vosoughi, Soroush, Deb Roy y Sinan Aral, «The spread of true and false news online», Science, 359, 1146-1151, 9 de Marzo de 2018, págs. 1-6.

57 Castells, Manuel y otros, «La Transición a la Sociedad Red», Barcelona, Ariel, 2007, pág. 23-41.

58 Recomendación 2/99 sobre la protección de la intimidad en el contexto de la intercepción de las telecomunicaciones, adoptada el 3 de mayo de 1999, 5005/99/Final, WP-18. En esta Recomendación, el Grupo de Trabajo del artículo 29 señala que cualquier intercepción de las 
y del rastreo automático y sistemático de las expresiones, tendencias, gustos y deseos de los ciudadanos en las redes sociales y en sus conductas de navegación por la red. En la actualidad merced al nuevo instrumental técnico y a la trazabilidad del tráfico de datos se tienen una acceso privilegiado al «yo cuantificado» de cada ciudadano que éste ha integrado voluntaria o involuntariamente en la matriz de datos que se vehiculiza a través de Internet como red global. Unas veces de forma consciente en lo que se ha dado en llamar la «extimidad» o exhibición pública de lo íntimo, concepto acuñado por Jacques Lacan y otras veces sacrificando la intimidad por una nueva dimensión virtual del narcisismo colectivo. Recordemos que Bentham diseñó una cárcel, el Panóptico en la que los prisioneros podían ser vistos en todo momento por sus guardianes merced al diseño de la prisión, sin estos poder ser vistos a su vez por los guardianes. Tal circunstancia implicaba que el preso se convierte en su propio observador y se contralará así mismo - autocensura - ya que no sabía si estaba siendo observado en cualquier momento por las autoridades de la prisión. Su comportamiento, a partir de ese momento, estará normalizado, institucionalizado por medio de la situación epistémica en la que el preso ha sido situado. El conocimiento perfecto del observador le confiere un poder total, un poder omnipresente, anónimo y constante. Los riesgos para la democracia de opinión no acaban sino de empezar, lo que en la doctrina norteamericana sobre libertad de expresión se conoce con el nombre de «Chilling Efect ${ }^{59}$ » (efecto de enfriamiento de la libertad de expresión) y que en

telecomunicaciones, definida como el conocimiento por un tercero de los datos sobre el contenido y el tráfico de las telecomunicaciones privadas entre dos o más corresponsales y, en especial, de los datos sobre tráfico relacionados con la utilización de servicios de telecomunicaciones, constituye una violación del derecho individual a la privacidad y a la confidencialidad de la correspondencia.

59 Realizaremos seguidamente unas breves precisiones sobre los fundamentos de la doctrina denominada «Chilling Effect», que obviamente no aparecen en la Sentencia del Tribunal Supremo de los Estados Unidos ACLU vs. RENO, sino como fruto de una larga tradición. Así, es preciso recordar que en el caso Broadrick v. Oklahoma, 413 US 601, 1973, el Tribunal Supremo delimita el concepto de normas que vulneran la Primera Enmienda, por un alcance excesivo, denominado overbreadth y/o una carencia de precisión, denominada vagueness, al establecer: «Se ha admitido desde hace tiempo que la Primera Enmienda precisa espacio para respirar, y que las leyes que pretenden obstaculizar o limitar el ejercicio de los derechos en aquella contemplados deben redactarse de manera ajustada (narrowly drawn). En resumen, una norma adolece del defecto deoverbreadth - cuando la aplicación de sus preceptos puede traducirse en una restricción o en un castigo de la libre expresión constitucionalmente protegida.» El segundo defecto, la imprecisión o vaguedad de la norma reguladora de la libertad de expresión implica la exigencia de una claridad meridiana en la descripción de la conducta afectada. Como estableció el Tribunal Supremo de los Estados Unidos en 1926: «una norma que prohíbe o requiere que se haga algo en términos tan vagos que hombres de inteligencia normal tengan que averiguar su significado y difieran respecto de su aplicabilidad viola lo primero y más esencial del principio de legalidad» (Conally v. General Const. Co., 269 US 385, 391, 1926). Varias razones se han invocado en favor de la aplicación de la doctrina de la nulidad por causa de vaguedad en el área de la libertad de expresión: «Una ley poco clara... puede disuadir a algunas personas... de expresarse... [Además], la ejecución de la ley por el gobierno debe estar presidida por claras orientaciones para evitar que los funcionarios actúen según su propia 
resumen no es sino la autocensura de los ciudadanos en el ejercicio de la libertad de expresión vigilada. Investigadores como David Lyons conscientes de los riesgos del Big Data han creado instituciones de investigación como el Surveillance Studies Centre $^{60}$ pero debemos precisar qué es el Big Data.

Para poder avanzar en nuestro estudio es imprescindible exponer con brevedad y rigor en qué consiste sintéticamente el Big Data para de esa forma disponer de los elementos de juicio necesarios que nos permitan adentrarnos en una tecnología compleja pero no inaccesible — como argumentara Erich Fromm ${ }^{61}$ — que es imprescindible desentrañar para averiguar cómo y para qué se procesa la información. Sin embargo parece procedente avanzar inicialmente un concepto central del Big Data y es que se trata de un conjunto de herramientas informáticas — de procesamiento de la información- destinadas a la predicción de las conductas humanas como precisan Ian Kerr y Jessica Earle ${ }^{62}$ de —analítica predictiva ${ }^{63}$ - a través del análisis de los datos que, como materia prima generan los usuarios de las redes transformando la información desarticulada en conocimiento estructurado. Debemos comprender previamente dos formas de procesamiento de la información. Antes de la invención de Internet como red de redes en los años 70 el procesamiento de la información era fundamentalmente autónomo en el sentido de que los sistemas informáticos procesaban la información que se les suministraba sin que esos sistemas tuviesen contacto o estuviesen conectados con otros sistemas de almacenamiento y procesamiento. A partir de la invención de Internet los sistemas de

discrecionalidad.» (Dombrowsky v. Pfister, 380 US 479, 1965, Steffel v. Thompson, 415 US 452 1974). La doctrina americana denomina a este doctrina «Chilling Effect» o efecto de enfriado para describir o significar el retraimiento (o autocensura) o la timidez en el ejercicio de los derechos reconocidos en la Primera Enmienda, ante el temor de posibles sanciones legales. Santiago Sánchez González, La libertad de expresión, Marcial Pons, 1992, pág. 38 y ss.

${ }^{60}$ Puede accederse al Centro y a sus investigaciones en: http://www.sscqueens.org/

(Última visualización 31 de Marzo de 2017).

${ }^{61}$ Como señalara Erich Fromm: «Con respecto a todos los problemas básicos de la vida individual y social, un amplio sector de nuestra cultura ejerce una sola función: la de confundir las cosas. Un tipo de cortina de humo (de larga tradición como podemos apreciar, añadimos nosotros) consiste en afirmar que los problemas son demasiado complejos para la comprensión del hombre común. Por el contrario, nos parecería que muchos de los problemas básicos de la vida individual y social son muy simples, tan simples que deberíamos suponer que todos se hallan en condiciones de comprenderlos. Hacerlos aparecer tan monstruosamente complicados que sólo un —especialistapuede entenderlos y eso únicamente en su propia y limitada esfera, produce — a veces de manera intencionada- desconfianza en los individuos con respecto a su propia capacidad de pensar sobre aquellos problemas que realmente les interesan. Los hombres se debaten impotentes frente a una maraña caótica de datos y esperan con paciencia patética que el especialista halle lo que debe hacer y a dónde debe dirigirse. Este tipo de influencia produce un doble resultado: por un lado, escepticismo y cinismo frente a todo lo que se diga o escriba, y, por el otro, aceptación infantil de lo que se afirma con autoridad». Erich Fromm, Op. cit., pág. 240.

${ }^{62}$ Ian Kerr, y Jessica Earle, «Prediction, Preemption, Presumption. How Big Data Threatens Big Picture Privacy» Stanford Law Review, n. ${ }^{\circ}$ 66, 3 Septiembre 2013, págs. 65-72.

${ }_{63}$ Schmarzo, Bill, Big Data. El poder de los datos, Wiley-Anaya, Madrid, 2014, pág. 117. 
procesamiento, antes aislados, empiezan a reconocerse y se conectan unos a otros mediante las redes y operan en matrices de procesamiento. A partir de ese momento aparece el concepto de «procesamiento distribuido». En vez de disponer de grandes ordenadores capaces de procesar inmensas cantidades de datos la potencia distribuida suma la potencia de procesamiento de miles o cientos de miles de máquinas, lo que conlleva ventajas ${ }^{64}$ como entre otras su resiliencia $^{65}$ frente a los fallos.

El Big Data se suele resumir en cuatro elementos caracterizadores que son los siguientes: Volumen; Velocidad; Variedad yVeracidad.

La primera V, el Volumen de datos hace referencia a la inmensa constelación de los millones de datos que se generan cada segundo en las redes tales como correos electrónicos, mensajes de twitter, video clips generados por todo tipo de cámaras de teléfonos, datos procedentes de millones de sensores, etc. En el momento presente esas cantidades se cifran en Zettabytes ${ }^{66}$. En redes como Facebook se generan diaria-

${ }^{64}$ _ Los sistemas informáticos y el acceso a la red son económicos. Los computadores personales actuales tienen una potencia superior a los primeros mainframes, además de tener mucho menor tamaño y precio. Unido al hecho de que la conexión a Internet está disponible universalmente y es económica, el gran número de computadores que existen interconectados se convierte en una comunidad descentralizada ideal para la computación distribuida.

- Cooperación en el uso de recursos. La arquitectura de la computación distribuida refleja la arquitectura de computación de las organizaciones modernas. Cada organización mantiene de forma independiente los sistemas informáticos de procesamiento y recursos locales, mientras permite compartir recursos a través de la red. Mediante la computación distribuida, las organizaciones pueden utilizar sus recursos de forma efectiva. La Web, por ejemplo, consiste en una plataforma muy potente para la compartición de documentos y otros recursos dentro y entre las organizaciones.

- Escalabilidad. En la computación primitiva de equipos no conectados a las redes, los recursos disponibles eran limitados por la capacidad nativa y autónoma de los sistemas informáticos. Por el contrario, la computación distribuida proporciona escalabilidad, debido a que permite incrementar el número de recursos compartidos según la demanda. Por ejemplo, se pueden añadir más computadores que proporcionen servicio de correo electrónico si se produce un incremento en la demanda de este servicio.

Tolerancia a fallos. Al contrario que la computación no distribuida, la computación distribuida permite que un recurso pueda ser replicado (o reflejado de forma que sea redundante) a fin de dotar al sistema de tolerancia a fallos, de tal forma que proporcione disponibilidad de dicho recurso en presencia de fallos. Por ejemplo, las copias o backups de seguridad de una base de datos se pueden mantener en diferentes sistemas de la red, de modo que si un sistema falla, se puede acceder al resto de las copias sin interrumpir el servicio. Aunque no es posible construir un sistema distribuido completamente fiable en presencia de fallos y más en redes abiertas sujetas a posibles ataques con muy diverso origen. La tolerancia a fallos en la computación distribuida es un tema complejo que ha recibido mucha atención en la comunidad científica ya que es uno de los pilares de su eficiencia.

${ }^{65}$ González de la Garza, Luis Miguel, Seguridad Nacional en la Cloud Computing (Computación en Nube y sus Riesgos), Actas III Jornadas de Estudios de Seguridad, Instituto Universitario Gutiérrez Mellado, págs. 1299-1321. Madrid, 2011,

${ }^{66}$ Un Zettabyte es un trillón de gigabytes. Para aclarar los datos de capacidad de procesamiento de la información, los términos más comunes son: mil megabytes (MB) equivalen a 1 gigabyte (GB); mil gigabytes equivalen a 1 terabyte (TB); mil terabytes equivalen a un petabyte (PT), mil petabytes equivalen a 1 exabyte (EB) y mil exabytes (EB) equivalen a 1 zettabyte (ZB). 
mente 10.000 millones de mensajes, los usuarios comparten 350 millones de fotografías y vídeos y señalan con el icono «me gusta» 4.500 millones de páginas. Estas cifras son diarias y crecen día a día y todos los días generándose cada minuto modificaciones conductuales en una red planetaria. Todos estos datos se almacenan en miles de servidores distribuidos a lo largo del mundo entero y son las fuentes de almacenamiento de la información de las que el Big Data extrae sus análisis predictivo en tiempo real.

La segunda V, la Velocidad se refiere a la velocidad con la que los nuevos datos son generados a nuestro alrededor. Se puede pensar en la velocidad con la que los mensajes que se producen en las redes se hacen virales, la velocidad con la que se registran millones de transacciones económicas en red y la velocidad con la que pueden detectarse fraudes en tiempo real. La velocidad que puede cifrarse en milisengundos con los que los sistemas automáticos pueden tomar decisiones deducidas del análisis de datos residentes en redes sociales. El Big Data hace posible el análisis de datos en tiempo real sin necesidad de analizar datos almacenados en bases de datos ya que la información se procesa tan rápido como ésta se produce.

La V de la Variedad hace referencia a los distintos tipos de datos que actualmente se pueden usar como la materia prima de procesamiento. Las bases de datos del pasado reciente se centraban en lo que se denominan «datos estructurados» es decir datos fundamentalmente correlacionados. Pensemos en los datos característicos de las hojas de cálculo, donde series de datos tenían claras correspondencias con procesos de la más variada índole. En la actualidad y en el mundo global de los datos de las redes, más del $80 \%$ de los datos se encuentran desestructurados, si bien es perfectamente posible su catalogación por tipos, categorías, fuentes, naturalezas, etc. Con las herramientas de procesamiento de datos que conocemos como Big Data se puede procesar tanto datos estructurados como no estructurados lo que incluye conversaciones de muchos participes en redes sociales que muestren tendencias, mensajes, datos procedentes de redes de sensores (la Internet de las cosas) video y la voz contenida en los videos, fotografías (lo que incluye los datos de geolocalización que como metadatos están a ellas incorporadas cuando no se deshabilita esa función, por ejemplo, en las cámaras de los teléfonos móviles). Estos datos permiten ofrecer nuevas métricas y usos de la información con relevancia política.

La V correspondiente a la Veracidad, es bastante más compleja de obtener, se refiere a la confianza o desconfianza de los datos que se obtienen. Como sabemos existen muchos tipos de datos, la precisión y calidad de éstos puede ser también evaluable. Las grandes cantidades de datos a menudo pueden compensar la falta de precisión o determinadas carencias de calidad. Sin embargo existen fuentes de datos de difícil evaluación como los post en las redes sociales, expresiones o giros coloquiales o lingüísticos territoriales en las conversaciones que, en ocasiones, hace más dificultosa la evaluación de la veracidad deducible de determinadas categorías de datos.

Los tipos de datos como materia objeto de procesamiento, con carácter general, pueden ser básicamente clasificados de dos grandes categorías que podríamos consi- 
derar como «datos de contenido» $\mathrm{y}$ «datos continente» o datos de tráfico. Las regulaciones normativas, como señalan Neil M. Richards y Jonathan H. King ${ }^{67}$ protegen los datos personales de contenido al establecerse una presunción bien fundada de que éstos son los que revelan o pueden revelar circunstancias personales directas de sus titulares que forman parte de la esfera íntima de la persona en el ámbito material, en cambio, no sucede lo mismo con los datos de tráfico. Acontece con éstos que siendo una categoría de datos «especiales» son el continente del contenido han recibido mucha menos atención por parte de la doctrina y por los ciudadanos y, sin embargo, son capaces de identificar e individualizar conductas, actitudes, movimientos, posiciones que asociados a los ciudadanos permiten reconstruir perfiles con una precisión extraordinaria tanto de información procesada por ordenadores personales como por teléfonos inteligentes como precisa Jonathan Mayer y otros. ${ }^{68}$ A esta conclusión se llego en los Estados Unidos en el procedimiento Klayman $v$ Obama $^{69}$ en el que la opinión del Tribunal de Distrito de Columbia al analizar si la obtención y procesamiento masivo de metadatos por la NSA entraba en colisión con de la Cuarta Enmienda, determinó el Tribunal que la recopilación masiva de estos violó una expectativa razonable de privacidad y, por lo tanto, fue una obtención de datos en contradicción con la citada Enmienda. En Aclu Vs. Clapper ${ }^{70}$ el tribunal, en cambio, no apreció incompatibilidad de la obtención de esos datos, sin embargo, los científicos que como Amicus Curiae ${ }^{71}$ presentaron un detallado informe sobre la naturaleza de los metadatos precisaron con extraordinaria claridad su inmensa capacidad para afectar severamente a la privacidad de los ciudadanos en sus comunicaciones electrónicas. De hecho sus conclusiones son válidas para el asunto Wikimedia Foundation v National Security Agency ${ }^{72}$ en el que vuelven a examinarse las interceptaciones masivas de metadatos por parte de los servicios de información en el ámbito de las comunicaciones internacionales de los norteamericanos.

Hemos vivido, en segundo lugar, un punto de inflexión en lo que respecta a la protección de los derechos a la intimidad y al secreto de comunicaciones y ese momento tiene un claro origen en los atentados terroristas del $11 \mathrm{~S}$ en los Estados Unidos producidos en el año 2001. Desde ese momento se han invertido invariablemente la protección de estos derechos. El terrorismo ha conseguido transformar nuestras sociedades de sociedades abiertas y en general libres, en sociedades con miedo en las que se sacrifican amplias parcelas de libertad a una incierta y no demostrada seguridad en

${ }^{67}$ Richards, Neil M y Jonathan H. King, «Big Data Ethics» Wake Forest Law Review, Vol. 49, USA, 2014, págs. 393-432.

68 Jonathan Mayer, Patrick Mutchler y John C. Mitchell, «Evaluating the privacy properties of telephone metadata», PNAS 2016 May, 113 (20), págs. 5536-5541.

69 Civil Action No. 1:13-cv-00851 (RJL)

${ }^{70}$ Civil Action No 133994 (WHP)

${ }^{71}$ https://www.eff.org/press/releases/top-technologists-file-brief-supporting-aclu-lawsuit-againstnsa-spying (puede examinarse el informe, 3 de marzo de 2018)

72 No. 1:15-cv-00662-TSE 
la que, como acuñara el teólogo alemán Hermann Busenbaum, cum finis est licitus, etiam media sunt licita una vuelta o una reedición contemporánea de lo que se puede definir como Estado Neo-Policía de Derecho en el que la sospecha generada por la incerteza del temor y un enemigo difuso hace posible búsquedas proactivas de sospechosos virtuales por parte de los Estados, drenando de contenido y sustancia menguando en suma, Derechos medulares de una concepción liberal de Estado de Derecho vigoroso donde la presunción de inocencia cede frente a la sospecha. Esa pérdida es aceptada por la mayor parte de la sociedad acríticamente y con amplia resignación como ya advirtiera de alguna forma Etienne de la Boétie en su memorable «el contra uno o discurso sobre la servidumbre voluntaria $»^{73}$ más por ignorancia, advirtamos que por otras circunstancias, pero lo cierto es que son circunstancias las de la vigilancia sistemática y el control de todas las actividades de los ciudadanos en las redes de una gravedad, pensamos, que es extrema debido a que socaban los fundamentos de la libertad y con esta de la democracia, al ser precondiciones de otros derechos fundamentales y libertades públicas como la libertad de expresión. ¿Es posible una opinión pública libre en un medio que se basa en la vigilancia permanente de todo y de todos? tal vez Benjamin Franklin tenía razón cuando afirmaba que aquellos que cederían la libertad esencial para adquirir una pequeña seguridad temporal, no merecen ni libertad ni seguridad.

Parafraseando a Rousseau en el Capítulo VI, del Libro I del Contrato Social, sería preciso:

«Encontrar boy una forma de uso de los datos personales por la que se defienda y proteja con la fuerza común del Derecho nacional e internacional la persona y su dignidad en su dimensión virtual, y por la cual cada uno, uniéndose a todos, no pierda su individualidad, intimidad y secreto de sus comunicaciones permaneciendo y respetándose de forma integral la esfera de todos sus datos sin fragmentación alguna — su yo cuantificado_ de la misma forma en la que se protege en su dimensión no virtual».

Parece claro que se hace necesario en un mundo global un sistema de justicia global compuesto por un sistema judicial internacional como advirtiera Kelsen ${ }^{74}$ en su célebre utopía realista cada vez más eficiente y superador de soberanías herméticas y disfuncionales que en muchas ocasiones limitan severamente la eficiencia que una homogeneidad jurídica razonable representaría para Derechos Humanos Universales, singularmente en lo que respecta a la privacidad, un derecho como afirma Miguel Revenga en demolición y que precisa una reconstrucción dogmática de gran alcance ${ }^{75}$. Las rupturas quizás más graves que afectan a los derechos humanos se basan, en el momento presente y en el ámbito del que nos ocupamos, precisamente en las discon-

73 De la Boétie, Étienne, «Discurso de la servidumbre voluntaria», Tecnos, Madrid, 2014.

74 Kelsen, Hans, «La Paz por medio del Derecho», Trotta, Madrid, 2008, págs. 46-49.

75 Revenga Sánchez, Miguel «El derecho a la intimidad: un derecho en demolición (y necesitado de reconstrucción)», en: «El derecho a la privacidad en un nuevo entorno tecnológico», Cuadernos y Debates, Núm 248, CEPC, Madrid 2016, págs. 71-98. 
tinuidades jurídicas que los Estados soberanos presentan frente al concepto de no nacional o extranjero al cual se le inaplican las garantías quepara los nacionales se deberían aplicar en cada uno de los entornos nacionales con un desconocimiento grotesco, en muchas ocasiones, de la Carta Universal de los Derechos Humanos. ${ }^{76}$

Como declara la ONU expresa y contundentemente en su Informe sobre el Derecho a la Privacidad en la era Digital ${ }^{77}$ la disminución de los costos de tecnología y almacenamiento de datos ha eliminado los inconvenientes financieros o prácticos de la vigilancia. El Estado no babía tenido nunca la capacidad de que dispone actualmente para realizar actividades de vigilancia simultáneas, invasivas, con objetivos precisos y a gran escala. Es decir, las plataformas tecnológicas de las que depende crecientemente la vida política, económica y social a nivel mundial no solo son vulnerables a la vigilancia en masa sino que en realidad pueden facilitarla. Cuando existe un objetivo legítimo y se han establecido las salvaguardias apropiadas, puede permitirse a un Estado realizar actividades de vigilancia bastante perturbadoras; sin embargo, incumbe al gobierno demostrar que la injerencia es necesaria y proporcional al riesgo concreto de que se trate. Así pues, los programas de vigilancia en masa o "a granel» pueden considerarse arbitrarios, aunque persigan un objetivo legítimo y hayan sido aprobados sobre la base de un régimen jurídico accesible. En otras palabras, no es suficiente que las medidas tengan por objeto encontrar determinadas agujas en un pajar; lo importante es el impacto de las medidas en el pajar, en comparación con el riesgo de que se trate; es decir, si la medida es necesaria y proporcionada.

Como señala el informe a sensu contrario nos encontramos ante la desproporción de las medidas lo que es contradictorio con con la probibición del exceso ${ }^{78}$ que sirve para controlar la idoneidad de los instrumentos y medios de actuación empleados por el Estado, en cuanto establece el deber de los poderes públicos de utilizar aquellos medios e instrumentos que menos limiten la libertad de los ciudadanos y que se amparan caso de no tener tal principio debidamente en consideración una posible razón de Estado que invoca la Seguridad Nacional.

De lo anterior nos encontramos ante unas herramientas extraordinariamente precisas para predecir el comportamiento de los ciudadanos como argumentan Matz y colaboradores ${ }^{79}$ y un debilitamiento de la privacidad en las redes con lo que el acceso a los datos personales de los ciudadanos, por ejemplo, en la dimensión de datos de tráfico son de acceso público a las empresas y Estados que disponen de esa información de forma masiva. La posibilidad de una clasificación de los ciudadanos en ideologías, niveles de renta, tipos de conducta expresadas por un seguimiento preciso o constan-

76 Resolución 217 A (III), de 10 de diciembre de 1948 hecha en París.

$77 \mathrm{~A} / \mathrm{HRC} / 27 / 37 \mathrm{El}$ derecho a la privacidad en la era digital. Informe de la Oficina del Alto Comisionado de las Naciones Unidas para los Derechos Humanos,30 de junio de 2014.

${ }^{78}$ Kluth Wilfred, «Probibición del exceso y principio de proporcionalidad en Derecho Alemán», Cuadernos de Derecho Público, n. ${ }^{\circ}$ 5, septiembre-diciembre, 1998, págs. 220-237.

79 S. C. Matz, M. Kosinski, G. Nave and D. J. Stillwell, «Psychological targeting as an effective approach to digital mass persuasion», PNAS 2017 November, 114 (48) pág. 12714-12719. 
te de sus intereses mediante precisos algoritmos, lo que dicen, con quién y cómo se relacionan, hacen posible la sociedad «clasificada» de la que se pueden predicar notables riesgos en lo que respecta a su posible manipulación por los poderes económicos privados y políticos. Ya que a partir de ese momento el hombre se transforma de sujeto de derechos en un «objeto» cuantificado y evaluable, predecible en términos económicos y políticos. Se transforma por ello en una «cosa» que sacrifica injustificadamente su dignidad como persona. Recordemos con Ronald Dworkin que tiene sentido decir que un hombre tiene un derecho fundamental contra el Gobierno, en el sentido fuerte, como la libertad de expresión, la intimidad, o el secreto de las comunicaciones si ese derecho o derechos son necesarios para proteger su dignidad o su status como acreedor a la misma consideración y respeto o algún otro valor personal de importancia similar; de cualquier otra forma no tiene sentido. De modo que, si los derechos tienen sentido, la invasión de un derecho relativamente importante debe ser un asunto muy grave, que significa tratar a un hombre como a algo menos que un hombre, o como menos digno de consideración que otros hombres. La institución de los derechos se basa en la convicción de que ésa es una injusticia grave y que para prevenirla vale la pena pagar el coste adicional de política social o eficiencia (en el caso que nos ocupa, añadimos) que sea necesario, ${ }^{80}$ porque el hombre en expresión de Kant no puede ser utilizado únicamente como medio por ningún hombre, ni por otros, ni siquiera por sí mismo, sino siempre a la vez como fin y en eso consiste precisamente su dignidad (la personalidad) elevándose sobre las cosas ${ }^{81}$. Otra vertiente diversa del exceso en la cuantificación es el defecto de la misma, es decir, aquellas personas que no son cuantificadas verosímilmente serán excluidas de procesos inclusivos y pueden ser discriminadas como argumenta Jonas Lerman ${ }^{82}$.

Hemos hecho referencia a los algoritmos y debemos precisar que, en la sociedad de la información estos son esenciales, porque son las herramientas software que «toman las decisiones» y nada garantiza que el tratamiento de la información sea neutral en las valoraciones que efectúen estas herramientas. Esa es la razón por la que la Resolución sobre perfiles, adoptada en la 35 Conferencia internacional de autoridades de protección de datos y privacidad ${ }^{83}$ se señalaba expresamente en su tercer punto que «se debe garantizar que los perfiles y los algoritmos subyacentes estén sujetos a validación continua, con el fin de permitir la mejora de los resultados y la reducción de resultados falsos positivos o negativos» así como en el punto sexto en el cual se pedía a los Gobiernos de todo el mundo que «se asegurare que todas las operaciones de perfilado estén sujetas a una supervisión apropiada». Pese a ello, la realidad es muy

80 Dworkin, Ronald, «Los derechos en serio», Ariel, Barcelona, 1997, pág. 295.

81 Kant, Inmanuel, «La metafísica de las costumbres», Tecnos, Madrid, 1994, pág. 335.

82 Lerman, Jonas, «Big Data and Its Exclusions» (September 3, 2013). Stanford Law Review Online, 66 Stanford Law Review Online 55 (2013). Disponible en SSRN: https://ssrn.com/abstract=2293765 or http://dx.doi.org/10.2139/ssrn.2293765

83 Resolución sobre perfiles, 35 th International Conference of Data Protection and Privacy Commissioners Privacy: A Compass in Turbulent World, Warsaw, Polonia, 23-26 de Septiembre de 2013. 
distinta, la opacidad de los algoritmos, protegidos como secretos industriales en la mayoría de los casos no permite conocer en absoluto el tratamiento que recibe la información y hay razones para dudar, como argumentan Dwork y Mulligan ${ }^{84}$ de su neutralidad. Lo que puede conducir a resultados gravemente atentatorios al discriminar a los ciudadanos en múltiples dimensiones y formas posibles, eso es precisamente lo que trata de mitigar la Resolución sobre Big Data elaborada en la 36 Conferencia Internacional de autoridades de protección de datos y privacidad ${ }^{85}$ en la que se indica en su punto once que se deberá «demostrar que las decisiones respecto al uso del Big Data son justas, transparentes y responsables. Relacionado con el uso de datos para fines de creación de perfiles, tanto éstos como los algoritmos en que están basados requieren una valoración continua. Este proceso necesita revisiones regulares para verificar si los resultados de la creación de perfiles son responsables, justos y éticos y si son compatibles y proporcionados con el propósito para el cual los perfiles son usados. Debe evitarse la injusticia con las personas debido a resultados completamente automatizados que arrojen un falso positivo o un falso negativo. Siempre debe estar disponible una valoración manual de resultados con efectos significativos para los individuos».

\subsubsection{Los perfiles psicométricos}

Los datos que se recogen de las interacciones de los usuarios de los servicios de Internet $^{86}$ (lo que incluye todo tipo de plataformas, desde motores de búsqueda como Google a redes sociales como Facebook) son extraordinariamente amplios incluyendo, naturalmente, los hábitos de navegación, las búsquedas que se efectúan, los enlaces que se siguen, hasta donde se siguen y qué se hace, ve, o expresa en los mismos. El tiempo que se dedica en cada sitio, los ficheros que se suben o se bajan, etc., son datos sistemáticamente registrados por lo que se denominan datos de «tráfico y facturación» que individualizan perfectamente a un usuario ya que son el «molde electrónico virtual de absolutamente todos los movimientos en la red desde que se conecta hasta que se desconecta un usuario de Internet apagando el ordenador». Datos análogos generan los teléfonos móviles que son en suma miniordenadores conectados a un teléfono y generando en éstos casos datos permanentes de geoposicionamiento es decir, de dónde está en cada momento el titular del dispositivo que también forman parte de la categoría de «datos de tráfico». Cuando en Facebook ${ }^{87}$ un usuario efectúa una acción tan aparentemente inocente o

${ }^{84}$ Dwork, Cynthia y Deirdre K. Mulligan, «It`s Not Privacy, and It`s not fair», Stanford Law Review, Vol. 66: 35, 3 de Septiembre de 2013, págs.35-39.

${ }^{85}$ Resolución sobre Big Data elaborada en la 36 th Conferencia Internacional de autoridades de protección de datos y privacidad, Balaclava Fort, Mauritania, 13 a 16 de Octubre de 2014.

${ }^{86}$ Lambiotte, Renaud y Michal Kosinski, «Tracking the Digital Footprints of Personality» Proceedings of the IEEEVol. 102, No. 12, Diciembre de 2014.

87 Vale exactamente igual en Twitter o en cualquier otra red social. 
neutral como la aprobación de un contenido, la «manita con el dedo pulgar hacia arriba, que indica que me gusta» esos datos se pueden recoger con gran facilidad y de forma automatizada para elaborar psicometrías ${ }^{88}$ o perfiles psicométricos que, conjunta o separadamente de otros datos de la persona y de los grupos con los que se relaciona ${ }^{89}$ permiten obtener con una precisión, en muchos casos superior al $95 \%{ }^{90}$ datos personales sensibles como: orientación sexual, etnicidad, opiniones religiosas y políticas, rasgos de personalidad como inteligencia, felicidad, tipos y susceptibilidad a adicciones a sustancias, separación de los padres, género, estado de gestación, como señalan Kosinski y colaboradores ${ }^{91}$.

Podría pensarse que esos datos psicométricos son menos precisos que los que se podrían recoger u obtenerse de un evaluador humano de la personalidad, pero los datos demuestran de forma consistente que no es así, los datos que se obtienen de nuestras interacciones privadas son más precisos como argumentan Youyoy, Kosinski y Stillwell ${ }^{92}$. De forma análoga a una encuesta en la que el encuestado tiene la oportunidad no decir la verdad, las actividades que se realizan en la Web describen con precisión los comportamientos reales, es decir, se registra «lo que de verdad se hace, no lo que se dice que se hace» y de esa forma la conducta real es la que se evalúa psicométricamente, razón por la que las encuestas y las estadísticas derivadas de aquellas están perdiendo terreno, como precisa William Davis ${ }^{93}$ frente a la minería de datos que alimentan la analítica predictiva y que conjuga los datos obtenidos por el Big Data y su articulación en los perfiles psicométricos que estamos considerando. Lo que para el autor significa un nuevo tiempo en el que las compañías privadas están ganando un poder inmenso que pone en riesgo las democracias. La respuesta a la pregunta de por qué se está poniendo en riesgo la democracia puede exponerse con algún ejemplo reciente que permite advertir los riesgos a los que se refiere Davis y, en particular, y en lo que aquí nos interesa responder a la pregunta de para qué se utilizan esos perfiles psicométricos. Antes no obstante de avanzar es de interés señalar que los datos

${ }^{88}$ Cualquier usuario puede descargar la aplicación http://dataselfie.it/\#/download que opera como una extensión del navegador Google Chrome, y puede tanto rastrear su propia actividad de navegación como observar, cómo la aplicación con metodología OCEAN elabora un perfil psicométrico de su actividad.

89 Como hábitos de compra, a que centros religiosos asisten, propiedades mobiliarias e inmobiliarias de los sujetos, a qué revistan están suscritos, cómo diversifican su ocio, y un largo etcétera de datos con los que se pueden cruzar los perfiles y obviamente actualizarlos.

90 Para determinadas categorías de datos.

91 Kosinski, Michal, David Stillwell, y Thore Graepel, «Private traits and attributes are predictable from digital records of human behavior», PNAS, vol. 110, N. ${ }^{\circ}$ 15, April 9, 2013, págs. 5802-5805.

92 Youyou Wu, Michal Kosinski, y David Stillwell, «Computer-based personality judgements área more accurate than those made by humans», PNAS, vol. 112, N. ${ }^{\circ} 4$, January 27, 2015, págs 1036-1040.

93 Davies William. »How statistics lost their power and why we should fear what comes next. The ability of statistics to accurately represent the world is declining. In its wake, a new age of big data controlled by private companies is taking over and putting democracy in peril», The Guardian, Thursday 19, January 2017 (20 de Agosto de 2017), puede verse en: https://www.theguardian.com/ politics/2017/jan/19/crisis-of-statistics-big-data-democracy 
obtenidos en la Web se introducen actualmente en dos tipos de cuestionarios o test psicométricos para el estudio del comportamiento, el OCEAN (Openness to experience; Conscientiousness; Extraversion; Agreeableness; Neuroticism ${ }^{94}$ ) y el IPIP (International Personality Item Pool) fundamentalmente, con 20 ítems, a través de los cuales se trata de obtener los perfiles psicométricos que se emplearan para una catalogación de las personas a través de la elaboración de tipologías sociodemográficas aptas para servir a finalidades políticas como la propaganda electoral. Recientemente y en los Estados Unidos una empresa privada Cambridge Analytica ${ }^{95}$ que ha desarrollado las campañas electorales de Donad Trump, Ted Cruz, John Bolton, o Ben Car-

94 Apertura a la experiencia: (inventiva / curioso vs. consistente / cauteloso). Aprecio por el arte, la emoción, la aventura, ideas inusuales, curiosidad y variedad de experiencia. La apertura refleja el grado de curiosidad intelectual, la creatividad y una preferencia por la novedad y la variedad de una persona tiene. También se describe como la medida en que una persona es imaginativa o independiente, y representa una preferencia personal por una variedad de actividades sobre una rutina estricta. La alta apertura puede ser percibida como impredecibilidad o falta de enfoque. Además, se dice que los individuos con alta apertura buscan la auto-actualización específicamente buscando experiencias intensas y eufóricas, tales como paracaidismo, vida en el extranjero, juegos de azar, etcétera. A la inversa, aquellos con poca apertura buscan alcanzar el cumplimiento a través de la perseverancia y se caracterizan como pragmáticos e impulsados por los datos, a veces incluso percibidos como dogmáticos y cerrados. Conciencia: (eficiente / organizado vs. desorganizado o descuidado). Una tendencia a ser organizados y confiables, mostrar autodisciplina, actuar de forma obedientemente, aspirar a logros y preferir el comportamiento planificado en lugar de espontáneo. La alta conciencia se percibe a menudo como obstinación y obsesión. La baja conciencia se asocia con la flexibilidad y con la espontaneidad, pero también puede sugerir descuido y la falta de fiabilidad de la persona. Extraversión: (saliente / enérgico vs. solitario / reservado). La energía, las emociones positivas, el surgimiento, la asertividad, la sociabilidad y la tendencia a buscar la estimulación en compañía de otros, y la locuacidad. La alta extraversión se percibe a menudo como la búsqueda de la atención, y la dominación. La baja extraversión causa una personalidad reservada y reflexiva, que puede ser percibida como distante o reservada. Agradecimiento: (amistoso / compasivo vs. desafiante / separado). Una tendencia a ser compasivo y cooperativo más que sospechoso y antagonista hacia otros. También es una medida de la naturaleza confiada y útil de la persona, y si una persona está generalmente bien temperada o no. El alto grado de amabilidad se ve a menudo como ingenuo o sumiso. Las personalidades de bajo nivel de condescendencia son a menudo personas competitivas o desafiantes, que pueden ser vistas como argumentativas o de baja confianza. Neuroticismo: (sensible / nervioso vs. seguro / inseguro). La tendencia a experimentar emociones desagradables fácilmente, como la ira, la ansiedad, la depresión y la vulnerabilidad. El neuroticismo también se refiere al grado de estabilidad emocional y control de impulsos y es a veces referido por su baja calificación como «inestabilidad emocional». Una alta necesidad de estabilidad se manifiesta como una personalidad estable y tranquila, pero puede ser vista como poco inspiradora y despreocupada. Una baja necesidad de estabilidad provoca una personalidad reactiva y excitable, a menudo individuos muy dinámicos, pero pueden ser percibidos como inestables o inseguros. Farnadi, G., Sitaraman, G., Rohani, M., Kosinski, M., Stillwell, D., Moens, M., Davalos, S.,\& De Cock, M. «How are you doing? Emotions and Personality in Facebook» 22 nd International Conference on User Modelling, Adaptation and Personalization (UMAP), 2014.

95 https://ca-political.com/ Como consecuencia del escándalo internacional con respecto a las estrategias de procesamiento de datos que desarrollaba esta empresa, Cambridge procedió al cierre táctico de la organización trasladando personal y activos a las empresas: Emerdata LTD y Auspex International, con la intención de camuflar sus actividades. http://www.auspexinternational.com/what-we-do.html. Otra organización norteamericana que desarrolla este tipo de actividades es Palantir https://www. palantir.com/

N. ${ }^{\circ} 103$, septiembre-diciembre 2018, págs 257-302 
son, emplea las tecnologías que venimos estudiando. Cambridge Analytica indica que posee datos de más de 230 millones de votantes en los Estados Unidos con un máximo de 5000 elementos o datos de cada uno de estos votantes ${ }^{96}$ lo que es perfectamente posible porque la generación de datos de tráfico es inmensa ${ }^{97}$. Con esos datos elaboran los perfiles sociodemográficos que condensan en 20 modelos de datos personalizados que pueden ser utilizados para pronosticar el comportamiento de los votantes. Pronosticar el comportamiento del votante es una circunstancia realmente novedosa ${ }^{98}$ que hace posible la ciencia de los datos en las campañas electorales, pero con ser esto importante, lo es más si cabe, el diseño de estrategias de campaña electoral basadas precisamente en la personalidad del elector.

\subsubsection{La propaganda cognitiva electoral y el microtargeting}

Como podemos apreciar la propaganda computacional es ya una realidad como precisan entre otros Wooley y Howard ${ }^{99}$ si bien lo novedoso del tipo de propaganda que estamos examinando no es que sea una propaganda pasiva sino que es una propaganda que podríamos denominar activa e inteligente debido a que se aprovecha de los sesgos caracterológicos de los votantes para diseñar una campaña de muy alta granularidad a medida del elector y de sus preferencias. Si, por ejemplo, es un elector que se ha abstenido en otras elecciones pueden ofrecérsele argumentos basado en sus preferencias emocionales para que vote. Podemos pensar en votantes que expresen caracteres que puedan ser explotables por agentes de propaganda automatizada, votantes que no tienen una clara preferencia y a los que este tipo de propaganda puede «seguir» de forma que mediante el «microtargeting» éste busque al elector para ofrecerle propaganda activa de su agrado, capaz de aprender de la interacción con el votante en base a su personalidad y readaptarse y refinarse en función de las respuestas del votante a un diálogo virtual que con anterioridad al advenimiento de estas tecnologías era inexistente.

Se denomina microtargeting porque tiene por objetivo agrupar a los electores en muy pequeños segmentos o clusters $^{100}$ sincronizados con los 20 modelos de tipos

96 https://ca-political.com/ca-advantage

97 Datos que, por ejemplo, en los Estados Unidos y en materia electoral recopila y organizan empresas como Catalist: https://www.catalist.us

${ }^{8}$ Si bien algunas de estrategias fueron puestas en práctica en la campaña del Presidente Barak Obama en el año 2012, como recuerda Sasha Issenberg, en la revista del MIT Technology Review, de 16 de Diciembre de 2012. https://www.technologyreview.com/s/508836/how-obama-used-big-datato-rally-voters-part-1/ (20 de Agosto de 2017)

99 Woolley, Samuel C, y Philip N. Howard, «Computational Propaganda Worldwide: Executive Summary», Working Paper No. 2017.11, Computational Propaganda Research Project. Oxford University. UK.

100 De tipo sociodemográfico como distritos electorales o circunscripciones específicas disputadas, en las que pocos votos pueden producir la asignación de un escaño y en los que una actividad de propaganda cognitiva puede justificar un esfuerzo suplementario de campaña electoral para conducir a votantes que dudan en si ejercerán o no su voto a ser motivados a decantarse hacia una tendencia electoral determinada. 
de personalidades o perfiles psicométricos ya elaborados a los que se dirige este tipo de propaganda electoral. Para que la información personalizada alcance y siga a su objetivo electoral. Es usual observar en cualquier navegación por Internet que tras visitar un comercio virtual posteriormente aparece en nuestros ordenadores o teléfonos móviles información del producto o servicio que hemos visitado anteriormente, en horas, días o semanas anteriores, la publicidad sigue al navegador en determinadas páginas Web merced al uso de cookies ${ }^{101}$ previamente aceptadas e instaladas en los equipos de los usuarios en los que ésta publicidad «que nos busca y acompaña» aparece. Ese seguimiento sería el equivalente del microtargeting electoral en su dimensión comercial. Pero a diferencia de ese microtargetin comercial, el electoral interactúa y aprende del elector al que tratará de persuadir con argumentos racioemocionales intentando imitar los intereses personales, sociales y emocionales de éste y ofrecer al mismo, variantes de campaña propagandística adaptadas a su perfil psicológico. Los experimentos de manipulación y contagio masivo de emociones en las redes sociales como el que se produjo en Facebook el año 2012 y que afecto a 700.000 sujetos como estudiaron Kramer, Guillory y Jeffrey T. Hancock ${ }^{102}$ demuestran convincentemente la gran efectividad de lo que se puede lograr en el ámbito de la transformación de motivaciones y preferencias mediante contagio emocional inducido.

En la reciente campaña electoral de Donald Trump, Cambridge Analytica tal y como señala Carol Cadwalladr ${ }^{103}$ estaba empleando entre cuarenta y cincuenta mil variantes de diferentes argumentos electorales informativos de los que se medía su respuesta en tiempo real de los destinatarios, readaptándose a sus respuestas de forma evolutiva. La granularidad de las acciones de estos mensajes están estructuradas por áreas geográficas de hasta una radio de 5 millas en las que se agrupan los perfiles psicográficos ${ }^{104}$ que se evalúan por el algoritmo de Cambridge Analytica, cuyo origen se encuentra en la Universidad de Cambridge ${ }^{105}$. Además, las variantes de los mensajes propagandísticos empleados actualmente no pueden ser conocidos por otros electores ya que se basan, por ejemplo en Facebook, en las publicaciones invisibles ${ }^{106} \mathrm{O}$ dark post que inicialmente fueron y son un instrumento para la publicidad personali-

101 López Jiménez, David, «Las cookies como instrumento para la monitorización del usuario en la red: La publicidad personalizada», Ciencias Económicas 29, n. ${ }^{\circ}$ 2, 2011.

102 Kramer, Adam D.I, Jamie E. Guillory y Jeffrey T. Hancock, «Experimental evidence of massive-scale emotional contagion through social networks», PNAS, Vol. 111, n. ${ }^{\circ} 24,17$ de Junio 2014, págs 8788-9790.

103 Cadwalladr, Carole, «Google, democracy and the truth about internet search» Internet, The Observer, 4 de Diciembre de 2016. https://www.theguardian.com/technology/2016/dec/04/googledemocracy-truth-internet-search-facebook(20 de Agosto de 2017)

104 La segmentación psicográfica es una herramienta que permite profundizar en los grupos de referencia para encontrar sus motivaciones de voto.

${ }_{105}$ El lector puede experimentar un análisis psicográfico básico de sus redes sociales con este algoritmo en: https://applymagicsauce.com/

${ }^{106}$ https://www.facebook.com/business/a/online-sales/unpublished-page-posts(20 de agosto de 2017) 
zada pero que también se puede emplear en las campañas electorales cognitivas personalizadas y que son de difícil fiscalización por una futura autoridad electoral.

Wolley y Howard ${ }^{107}$ señalan y, nos adherimos a sus conclusiones, que la propaganda computacional es una de las herramientas más poderosas contra la democracia ya que hace posible una genuina y nueva forma de «ingeniería social» capaz de romper por completo los modelos de opinión pública y de su manipulación como han estudiado Robert M. Bond, Christopher J. Fariss y colaboradores ${ }^{108}$. En efecto, los sistemas propaganda cognitiva electoral parece que funcionan en paralelo a poderosas y profundas distorsiones de la opinión pública que están siendo originadas por muy diversos grupos de interés de alcance nacional e internacional capaces de modificar, por ejemplo, mediante granjas de ordenadores la agenda de la opinión pública en temas de interés político mediante la manipulación de tendencias basadas en generación de hashtags hasta lograr posicionamientos como Trending Topics. Si bien, esas tendencias son creadas de forma artificial e intencionada tanto por las señaladas granjas de ordenadores como por bots ${ }^{109}$ automatizados u otros vectores tecnológicos de generación y difusión al servicio de sus creadores. El fenómeno ha sido estudiado por Bradshaw y Howard ${ }^{110}$ en el contexto internacional hallándose un cuerpo de evidencias muy preocupante ya que la principal tarea de estas plataformas, que fue en su origen dar forma a la opinión pública a través del uso de «narrativas dinámicas» para combatir la propaganda diseminada en las redes por las organizaciones terroristas, ha cambiado en la actualidad alcanzado otras actividades completamente diversas como las de naturaleza política al demostrarse una efectividad o eficacia de estas técnicas en finalidades distintas de para las que fueron originariamente diseñadas. Ejemplo de lo señalado es la reciente actividad de Rusia en su programa de desestabilización social occidental y erosión intencional de la opinión pública en campos sensibles como el de la vacunación, promoviendo activamente las campañas de desinformación dirigidas a fortalecer a los grupos anti vacunación mediante mensajes falsos realizados por trolls y bots automatizados sofisticados, como demuestra Broniatowski y colaboradores ${ }^{111}$. La opinión pública virtual está siendo un campo abonado para la experimentación social con fines de desestabilización de las democracias occidentales, hoy quizá se

107 Woolley, Samuel C, y Philip N. Howard Op Cit, pág. 7.

108 Bond, Robert M, Christopher J. Fariss, Jason J. Jones, AdamD.I.Kramer, Cameron Marlow, Jaime E. Settle\& James H. Fowler, «A 61-million-person experiment in social influence and political mobilization», Nature, Vol 489, 13 Septimbre 2012, pag.295-298.

109 Para una taxonomía de los diversos tipos de Bots aptos para ingeniería social, puede verse: Ferrara, Emilio, Onur Varol, Clayton Davis, Filipo Menczer y Alessandro Flamini, «The Rise of Social Bots», Communications of the ACM, Julio 2016, Vol. 59, n. ${ }^{\circ} 7$.

110 Bradshaw, Samantha y Philip N. Howard, «Troops, Trolls and Troublemakers: A Global Inventory of Organized Social Media Manipulation», Working paper n. ${ }^{\circ}$ 2017.12, Computational Propaganda Research Project, Oxford University, UK.

111 Broniatowski David A, Amelia M. Jamison, SiHua Qi, Lulwah AlKulaib, Tao Chen, Adrian Benton, Sandra C. Quinn, Mark Dredze. «Weaponized Health Communication: Twitter Bots and Russian Trolls Amplify the Vaccine Debate». American Journal of Public Health, 2018. 
hacen más evidente que en otros momentos históricos aquellas palabras de Thomas Jefferson cuando señalara que el precio de la libertad es la eterna vigilancia.

Las denominadas «Fake News» o noticias falsas que para el World Economic Forum representa un riesgo muy importante para la humanidad ${ }^{112}$ forman parte de estas redes de desinformación en la era de la posverdad como advierte Theodor Schaarschmidt. ${ }^{113}$ Los datos señalan que muchas de estas noticias falsas, aparentemente son producidas por asociaciones de base social o de la sociedad civil lo que ha dado origen a la acuñación de la expresión "astroturfing» ${ }^{114}$ pero en realidad tras ellas parece encontrarse la actividad de otras organizaciones que las emplean como pantalla de sus actividades políticas. ${ }^{115}$ La extensión de la actividad de estas redes de información falsa fue analizada en las elecciones a primarias en los EE.UU. de 2016. Jonathan Albright ${ }^{116}$ estudió la estructura de la topología de red y de dónde provenían los hipervínculos de esas noticias falsas, las cuales forman - expresándonos gráficamente- una estructura que envuelve desde redes pequeñas a los grandes centros de generación de información impulsando tales comunicaciones a las redes sociales como Facebook que, debido a sus algoritmos de clasificación de noticias, magnifican lo que proviene de tales redes. Ciertamente y como argumenta O'Reilly ${ }^{117}$ la influencia de las noticias falsas es una clara demostración del mal funcionamiento de los algoritmos.

Estos sitios han creado un ecosistema de propaganda en tiempo real: incluyen motores de generación de noticias falsas que intentan influir y pueden moldear instantáneamente la opinión pública a través de la «reacción» masiva a temas políticos serios y eventos noticiosos Albright rastreó 306 webs de noticias falsas y para comprender como estaban todas ellas conectadas entre sí y con el sistema de noticias de fuentes solventes, encontró una red de 23.000 páginas Web y 1,3 millones de hipervínculos. Estas redes se activan a petición para difundir información falsa viralizada,

112 The Global Risks, Report 2018, 13 th Edition, World Economic Forum, págs. 48-51. Puede obtenerse en: http://reports.weforum.org/global-risks-2018/digital-wildfires/

113 Schaarschmidt, Theodor, «La era de la posverdad», Mente y Cerebro, n. ${ }^{\circ}$ 87, 2017, págs. 22-28.

114 El concepto es una expresión que hace referencia a campañas de publicidad en el ámbito de la propaganda electoral, pero también se emplea en marketing, se trata de anuncios comerciales o propaganda que pretenden dar una impresión al receptor de espontaneidad, como si esa información proviniese de una relación directa con el entorno social. El nombre, como tal, proviene de un doble juego de palabras en inglés, partiendo del concepto de grassroots (literalmente «raíz de hierba», figurativamente «de base»). Este concepto sirve para calificar a los movimientos «con base social», que surgen «de abajo, de la sociedad», de la interacción de los miembros de una comunidad social. De otro lado, Astro Turf es una famosa empresa estadounidense de césped artificial cuyos productos están diseñados para parecer hierba natural. Así, astroturfing hace referencia a esa artificialidad, a esa falsa base social de ciertas campañas de marketing.

115 Bradshaw, Samantha y Philip N. Howard, Op Cit, pág. 11.

116 https://medium.com/@d1gi/the-election2016-micro-propaganda-machine-383449cc1fba (20 de Agosto de 2017)

117 O`Reilly, Tim, «La economía WTF, el futuro que nos espera y por qué depende de nosotros», Deusto, Barcelona, 2018, pág. 225. 
tendenciosa y políticamente orientada. Alcott y Gentzkow ${ }^{118}$ llegaron a conclusiones parecidas basándose en estudios estadísticos y Martin Moore ${ }^{119}$ considera que los gobiernos deberían adoptar medidas apropiadas para hacer frente a esta amenaza para la democracia. En efecto en democracias de opinión la generación de noticias falsas representa claramente la desvirtuación de un valor central para la creación de una opinión pública libre y correctamente informada como precisa Del Vicario y colaboradores $^{120}$ base para una participación responsable en la formación de la opinión y preferencias políticas de los ciudadanos. Lo señalado ha llevado en los Estados Unidos a que el 16 de febrero de 2018 el asesor especial del Departamento de Justicia ${ }^{121}$ Robert S. Mueller haya presentado una acusación criminal ante el gran jurado del distrito de Columbia contra las actividades de tres organizaciones rusas y de trece ciudadanos rusos por la presunta comisión de delitos federales de conspiración al intentar interferir en el sistema político de los Estados Unidos, lo que comprende la elección presidencial de 2016 en el marco de un proyecto de desestabilización de gran magnitud denominado Lakhta y que se basa en la generación de noticias falsas de origen Ruso como ya señalaron previamente en Europa Keir Giles, Uwe Hartmann y Debora Yarsike ${ }^{122}$.

La mayor parte de los datos que estamos considerando en relación con la información procesada mediante Big Data se obtuvieron de forma lícita solicitando autorización para su uso, otros muchos datos no y por lo tanto violarían la legislación vigente en Europa, pero no en los EE.UU. cuya regulación segmentada es más laxa como precisa Hoofnagle ${ }^{123}$ que la Europea pese a las insuficientes actualizaciones propuestas de la ECPA de $2017 .{ }^{124}$

No pudiendo aquí abordar esta importante materia, hay datos para pensar que el nuevo Reglamento UE 2016/679 del Parlamento Europeo y del Consejo, de 27 de abril de 2016 relativo a la protección de las personas físicas en lo que respecta al tratamiento de datos personales y a la libre circulación de estos datos y por el que se

118 Alcott, Hunt y Matthew Gentzkow, «Social Media and Fake News in the 2016 Election», National Bureau of Economic Research, Paper n. ${ }^{\circ}$ 23089, Enero de 2017.

119 Moore Martin, «Submission to: Inquiry into Fake News», Culture, Media and Sport Select Committee. Centre for the Study of Media, Communication and Power, King`s College London, 2017.

120 Del Vicario, Michela y otros «The spreading of misinformation online», $\underline{P N A S}, \mathrm{Vol} .113, \mathrm{n} .^{\circ} 3$, 2016, págs. 554-559.

121 https://www.justice.gov/opa/pr/grand-jury-indicts-thirteen-russian-individuals-and-threerussian-companies-scheme-interfere

122 Giles, Keir, «Handbook of Russian Information Warfare», NATO Defense College, Nov, 2016, Roma, págs. 33-76. Hartmann, Uwe, «The Evolution of the Hybrid Threat, and Resilience as a Countermeasure» Research Division, NATO Defense College, n. . . 139, Septiembre 2017, Roma, págs. 1-8. Yarsike Ball, Deborah, «Protection Falsehood With a Bodyguard of Lies: Putin`s Use of Information Warfare» Research Division, NATO Defense College, n. . 136, Febrero 2017, Roma, págs. 1-16.

123 Hoofnagle, Cris Jay,»Big Brother's Little Helpers: How Choice Point and Other Commercial Data Brokers Collect and Package Your Data for Law Enforcement», 29N.C. J. Int'l L. E Com. Reg.595 (2003), pág. 618. Puede consultarse en: http://scholarship.law.berkeley.edu/facpubs/678

124 https://www.congress.gov/bill/115th-congress/senate-bill/1657/text 
deroga la Directiva 95/46/CE (Reglamento general de protección de datos) no necesariamente protege adecuadamente los aspectos que hemos venido señalando, especialmente en lo que respecta al apartado 2. ${ }^{\circ}$ del artículo 9 en su letra e) en la cual podrían tener cabida los datos de tráfico, extraordinariamente útiles si no imprescindibles para la elaboración de perfiles de extraordinaria precisión.

Como hemos tratado de mostrar los sistemas de procesamiento de la información operan de forma cooperativa, el Big Data y la creación de perfiles psicométricos en el nuevo ecosistema electoral electrónico virtual, en el que las difusión de información falsa forma también un elemento apto para crear narrativas falsas destinadas a la generación de estados de opinión y ánimo que pueden combinarse con la propaganda cognitiva de muy diversas formas en una compleja alquimia electoral que al servicio de populismos escasamente escrupulosos representan un reto jurídico de extraordinaria magnitud para las democracias. En este sentido y en lo que respecta tanto a la propaganda difundida por «bots» como a la información falsa será preciso redefinir los límites jurídicos de lo admisible en campañas electorales como advierte Arnaudo${ }^{125}$ singularmente en lo que será quizá el punto más complejo a dilucidar, que no es otro que determinar si la actividad de personas privadas son y en qué medida se consideran actividades de propaganda en el nuevo marco que se abre en las campañas virtuales, como sucedió singularmente en las elecciones municipales de 2016 en Rio de Janeiro ${ }^{126}$.

\subsection{Poderes privados poderes públicos}

Podría perfectamente encuadrarse el significado profundo de la conversión de la privacidad en manos de empresas privadas en lo que Luigi Ferrajoli ha denominado con acierto como «Poderes Salvajes» ${ }^{127}$ y que otros autores como Michael J. Sandel advierten como la transformación de las economías de mercado, en «sociedades de mercado» ${ }^{128}$. En sentido parecido se pronuncia Sheldon S. Wolin cuando señala que un

125 Arnaudo, Dan, «Computational Propaganda in Brazil: Social Bots during Elections» Working Paper N. ${ }^{\circ}$ 2017.8, Computational Propaganda Research Project, pág. 24, University of Oxford.

126 Arnaudo, Dan, «Computational Propaganda in Brazil: Social Bots during Elections» Op Cit, págs. $19-26$.

${ }^{127}$ Ferrajoli hace referencia a la separación entre esfera pública y esfera privada, o sea, entre poderes políticos y poderes económicos. El cauce de esta confusión de poderes lo forman los conflictos de intereses generados por la estrecha alianza entre poderes públicos políticos y poderes económicos privados y por la substancial subordinación de los primeros a los segundos. Ferrajoli, Luigi, «Poderes Salvajes. La crisis de la democracia constitucional», Trotta, Madrid, 2011, pág. 53.

128 Para Sandel, la esencia sería la siguiente. Una economía de mercado es una herramienta, un instrumento valioso y eficaz para la organización de la actividad productiva, en cambio, una sociedad de mercado es un lugar donde casi todo está en venta, donde los valores del mercado empiezan a dominar todos los aspectos de la vida: la vida familiar, la salud, la educación, las relaciones personales, la ley, la política, la vida cívica. Puede verse su disertación en las conferencias TEDH https://www.youtube.com/ watch?v=3nsoN-LS8RQ (última visualización 25 de diciembre de 2016). 
hecho significativo de la política contemporánea es que mientras que el alcance de la autoridad reguladora del Gobierno ha retrocedido, el poder corporativo ha ido ocupando progresivamente funciones y servicios gubernamentales, muchos de los cuales solían considerarse áreas exclusivas del poder estatal. La privatización provee un componente fundamental de la democracia dirigida. Al ceder funciones esenciales que alguna vez fueron celebradas como victorias populistas, la privatización devalúa lo político y su contenido democrático. La estrategia que siguen los defensores de la privatización es, primero, desacreditar las funciones del bienestar social como «socialismo» y luego vender esas funciones a un oferente privado o bien privatizar un programa en particular ${ }^{129}$.

Los mercados no logran producir resultados eficientes por muy diversas razones que los economistas han explorado durante los últimos veinticinco años como argumenta Jean Tirole ${ }^{130}$ en la búsqueda de la economía del bien común. Los mercados están plagados de problemas de asimetrías de información y existen incentivos para que los participantes exploten y aumenten esas asimetrías, recuerdan, entre otros ${ }^{131}$ Joseph Stiglitz ${ }^{132}$ o Paul Ormerod ${ }^{133}$ razón por la que ignorar tal dato no conducirá sino a situaciones aberrantes si tal actividad carece de la necesaria regulación proactiva de los poderes públicos que aquí defendemos en el ámbito que estamos considerando. Esta experiencia debe proporcionarnos diversas consecuencias prácticas relevantes en materia de regulación y, entre ellas, no debe olvidarse que relajar el control de la regulación transfiriéndolo sin más a la autorregulación privada técnica, hace perder al Estado el control que tiene encomendado tutelar. Armonizar la lógica del sector privado: el ánimo de lucro o la mano invisible de Adam Smith con la lógica que preside la actividad del Estado: el bienestar público y el interés general y la mano visible de los valores y principios constitucionales de modo eficiente, ponderado y equilibrado no es tarea que se pueda delegar bajo la justificación pueril de que el Estado carece de instrumentos de regulación o técnicos de comprensión de los aspectos especializados objeto de regulación. Parece que el precio de esa autonomía regulatoria o en los extremos más patológicos soberanía regulatoria puede conducir y de hecho conduce a los efectos perversos de generación de externalidades negativas sistémicas inmensas que son lecciones de las que conviene tomar buena nota.

129 Wolin, Sheldon S., «Democracia S.A. La Democracia dirigida y el fantasma del totalitarismo invertido», Katz, Argentina, 2008, pág. 196.

130 Tirole, Jean, «La economía del bien común», Taurus, Barcelona, 2017, págs.47-64.

131 Wooley, Paul, «Por qué los mercados financieros son tan ineficientes y explotadores, y una propuesta de solución», Revista de Economía Institucional, Vol. 12, n. ${ }^{\circ}$ 23, Segundo semestre, 2010, págs. 55-83.

132 Stitglitz, Joseph, «Regulación y fallas», Revista de Economía Institucional, Vol. 12, n. ${ }^{\circ}$ 23, Segundo Semestre, 2010, págs. 13-28.

133 Ormerod, Paul, «La Crisis actual y la culpabilidad de la Teoría Macroeconómica», Revista de Economía Institucional, Vol. 12, n. ${ }^{\circ}$ 23, Segundo semestre, 2010, págs. 111-128. 
Señalado lo anterior no podemos, más aún no debemos olvidar o desconocer los argumentos históricos que señala atinadamente Stephen Holmes ${ }^{134}$ en relación con la renovada vigencia de un problema antiguo que cobra, en la actualidad, nuevo vigor. El perenne problema de la necesidad de acción Estatal para limitar la posible arbitrariedad de los poderes privados. De acuerdo con la versión recogida en los libros de texto, los teóricos europeos que tuvieron una mayor influencia en los Padres Fundadores de Estados Unidos eran tenaces antiestatistas. Veían en el Estado un agente coercitivo que debía ser limitado y en la sociedad civil una esfera de libertad que debía ser expandida. Mientras que consideraban que el sector público suponía una amenaza para la libertad y, por tanto, abogaban por su regulación, entendían que el sector privado era inofensivo, por lo que invitaban sólo a una benigna desatención. Pero ¿qué tan fiel resulta este retrato de los grandes teóricos europeos tan apreciados y emulados por los creadores de la Constitución de Estados Unidos? En una lectura de autores como Locke y Montesquieu no encontramos ningún rastro de una clara hostilidad contra el Estado, ni tampoco encontramos ninguna veneración de una esfera privada sin intervención. De hecho, lo que aprendemos es que sin autoridad la sociedad eventualmente colapsaría en un «estado de naturaleza» más o menos insufrible. La anarquía supone un riesgo tan grande para la libertad como la tiranía. La sociedad civil es, de hecho, una sociedad civilizada por el Estado. Como bien y penosamente sabían los teóricos de los siglos XVI y XVII, un gobierno mutilado expone a sus súbditos a bandas de forajidos asesinos. El «sector privado» debe ser severamente restringido por razones de seguridad. Entre los candidatos a una supresión pública justificada están los ejércitos privados, los tribunales privados y los impuestos privados, así como el derecho privado a declarar la guerra y el derecho privado al enjuiciamiento de criminales. La libertad sólo puede alcanzarse si se otorga a las autoridades públicas el monopolio de tan cruciales y delicadas funciones. No fueron Locke o Montesquieu, sino algunos personajes desaforados y algunos papistas desleales quienes desplegaron una ilimitada hostilidad contra el Estado. Los autores a los que admiraron y siguieron los constitucionalistas no se oponían a la autoridad en general, sino sólo a la autoridad abusiva y arbitraria; a la autoridad ilegítima en relación con el bien público. Aunque la soberanía era peligrosa y merecía desconfianza, la condición de carencia de soberanía no atemorizaba menos. Es más, el principal problema para el que se diseñaba un gobierno efectivo no era el «desorden». Caos y anarquía eran eufemismos de la opresión privada, del daño infligido al débil por el poderoso. La principal razón por la que «es imposible que la raza humana subsista, al menos en algún estado confortable y seguro, sin la protección del gobierno» es que, sin éste, la comunidad está a merced de los opresores privados. La dimensión redistributiva de la teoría del contrato social es, a menudo, pasada por alto incorrectamente. El paso del estado de naturaleza a la socie-

134 Holmes Stephen, «¿Restricciones liberales al poder privado?: Reflexiones sobre los orígenes y las justificaciones de la regulación del acceso a los medios de comunicación», Isonomia, n. ${ }^{\circ} 26$, Abril, 2007, pág. 7-48. 
dad civil presupone una redistribución de la seguridad orquestada por el Estado. La seguridad de los señores de la guerra se reduce — por ejemplo, se derriban sus murallas en el sistema Feudal - y se aumenta la seguridad que disfrutan la mayoría de sus conciudadanos. En otros términos, el contrato social no sólo impone la paz y produce orden, sino que reordena una grave desigualdad en las capacidades de los hombres para defenderse a sí mismos.

El poder privado supone una amenaza tan grande para la libertad como el poder público remarca Holmes. Esta es una fiel formulación del principio básico inculcado a James Madison y Thomas Jefferson por sus predecesores ingleses y franceses. La estricta no interferencia del Estado produciría no una competencia generalizada, sino monopolios depredadores. Sólo una autoridad soberana, burocrática y centralizada, puede tener la esperanza de domar al poder privado. Así pues, la libertad tan valorada por Locke y Montesquieu se distorsiona gravemente cuando es vista exclusivamente en términos de libertad «negativa». Estos teóricos no pretendían blindar completamente una esfera privada, colocándola fuera del alcance de los poderes públicos. Locke insiste en que la privacidad de la iglesia y del domicilio no protegen a los malhechores del brazo de la ley. Quienquiera que se encuentre en las condiciones de ser víctima de violencia o fraude, puede buscar un remedio en la autoridad pública. La libertad lockeana supone el acceso universal al poder del Estado. Los derechos lockeanos no son sólo escudos o diques de contención frente a la intervención del gobierno, incluyen la expresa titularidad del derecho a la intervención estatal para proteger a los individuos respecto del daño ocasionado por terceros. En los siglos XVI y XVII proteger al débil frente al fuerte suponía, entre otras cosas, la abolición de inmunidades tributarias y la distribución más equitativa de las cargas fiscales. El estado de naturaleza no sólo era desordenado, sino también injusto. En este sentido, la autoridad pública no tenía únicamente el propósito de establecer un orden, sino de producir un orden justo. Madison resulta inequívoco en este punto: «la justicia es el fin del gobierno. Es el fin de la sociedad civil». Desde luego, el concepto de justicia es resbaladizo, muy difícil de definir. Sin embargo, para los padres fundadores de la República norteamericana no significaba sólo la prevención del daño mutuo (por fuerza o fraude) y el cumplimiento de los contratos, sino que incluía, al menos, la idea más ambiciosa de un igual acceso a la justicia, norma incompatible con muchas relaciones «contractuales» manifiestas (por ejemplo, las que suponen una servidumbre permanente). Etimológicamente, los «privilegios» se refieren a «leyes privadas». La abolición de privilegios significa, pues, que lo privado y, por principio, el acceso especial debe ceder ante el igual acceso. La VI ${ }^{135}$ enmienda de la Constitución de Estados Unidos es un buen símbolo de esta dimen-

135 Enmienda VI. En toda causa criminal, el acusado gozará del derecho a un juicio público y expedito por un jurado imparcial del Estado y distrito en que el delito se haya cometido; distrito que deberá haber sido determinado previamente por la ley; así como a que se le haga saber la naturaleza y causa de la acusación; a que se le confronte con los testigos que depongan en su contra, a que se obligue a comparecer a los testigos que le favorezcan y a contar con la ayuda de un abogado que lo defienda. 
sión positiva de la libertad moderna. En una línea de pensamiento coherente con lo señalado se pronuncia Cass $\mathrm{R}$ Sunstein ${ }^{136}$ cuando advierte que la protección de la vida, la libertad y la propiedad era una tarea de los Gobiernos federal y estatales desde el punto de vista de los autores de la Constitución; y esa protección requería una acción gubernamental. En virtud del contrato social, el Gobierno debe proteger a la ciudadanía de la agresión privada ${ }^{137}$ proporcionando y redistribuyendo seguridad de forma efectiva, un propósito que apenas podía ser asegurado mediante la inmunidad de los controles gubernamentales. Por esa razón no sería plausible ver dicha inmunidad como el único objetivo del régimen constitucional, o entender la estructura gubernamental como la protección de los «derechos negativos» solamente. La protección gubernamental de la vida, la propiedad y el contrato sólo puede ser considerada como positiva en su carácter.

De lo anterior podemos extraer algunas ideas que son de aplicación al tema que nos ocupa. En efecto, son los poderes privados fundamentalmente quienes tienen un interés concentrado en hacer uso de los datos personales para finalidades económicas y políticas (Facebook, Yahoo, Google, Microsoft, Apple etc.) en múltiples dimensiones lucrativas como recordara Vilfredo Pareto ${ }^{138}$ que los sistemas regulatorios no son capaces de equilibrar adecuadamente y la perspectiva futura es aún peor ya que la nueva dimensión de la Internet de los objetos ${ }^{139}$ permitirá cuantificaciones aun notablemente más extensas (abarcará más componentes íntimos de la vida privada de las personas como los datos de biosalud) y precisas del «yo cuantificado» y por lo tanto el sacrificio de la privacidad alcanzará cotas de mayor impacto sobre los derechos fundamentales afectados. Pero con ser cierto lo anterior, a nuestro juicio, existe un riesgo igualmente preocupante serio y actual y que se encarna en que el Estado pueda participar directa o indirectamente en los poderes de control y de conocimiento de lo que estas tecnologías les pueden reportar con finalidades de genuino análisis social como

136 Sunstein, Cass R, «La revolución en los derechos: redefiniendo el Estado regulador», Ed Ramón Areces, Madrid, 2016, págs. 7-9

137 La cursiva es nuestra.

138 Como argumentara Vilfredo Pareto «si una determinada medida A (llamémosla protección deficiente de la protección de datos personales) provoca la pérdida de un euro a cada una de las personas de un grupo de mil, y una ganancia de mil euros a una sola, ésta última desarrollará una gran cantidad de energía mientras que las primeras se resistirán débilmente; y es probable que al final tenga éxito la que intenta conseguir los mil euros por medio de la medida $\mathrm{A}$ ». La influencia política en la búsqueda de ganancias económicas es un fenómeno muy real en el mundo en el que vivimos, como nos recuerda Sen. Para hacer frente a estas influencias no sólo hay que oponerse $-\mathrm{y}$ quizás incluso desenmascarar - a los buscadores de beneficios en los mercados cautivos, sino también abordar con seriedad sus argumentos intelectuales objeto de estudio. Adam Smith sostenía que los intereses creados tienden a salir ganando porque «conocen sus propios intereses» («no»el interés público a menudo difuso).

139 Vale también decir de los «sensores» ya que la idea es que los sensores se asociaran de forma estricta al titular de los servicios de forma que estos delinearan con total precisión la conducta de las personas en niveles de actividad insospechados. 
advirtiera atinadamente Norberto Bobbio $^{140} \mathrm{y}$, bajo la justificación de la seguridad del Estado, como manto protector que puede justificar cualquier injerencia desproporcionada ygravemente perturbadora en la vida de los ciudadanos, pueda expandirse a múltiples áreas de control social no justificadas — una nueva forma de ingeniería social- como conocer con detalle la ideología política de una buena parte de la sociedad conectada a las redes, al menos de aquella que se encuentre operando en las redes con perfiles en las redes sociales, por ejemplo y que se ha puesto de manifiesto el incidente internacional protagonizado por Edward Snowden. ${ }^{141}$ Así como los aspectos que hemos considerado con anterioridad como la propaganda cognitiva virtual en conexión con las noticias falsas. Todo ello sin olvidar el revelador contenido de la Sentencia C-362/14 de la Gran Salta del Tribunal de Justicia, de 6 de Octubre de 2015, caso Maximilliam Schrems en la que alto Tribunal declara las prácticas ilícitas de los servicios de información norteamericanos sobre los datos personales de los usuarios europeos procesados por empresas norteamericanas como Facebook. Pero no se trata de una posibilidad orientada hacia un individuo únicamente, lo que sería injustificable, sino que la tecnología hace posible la inserción de éste en grupos y controlarlos a estos en sus relaciones sistemáticas: manifestaciones, enlaces, estructura y las consecuencias que de ello es perfectamente posible derivar, su organización y previsibilidad de conductas, la sociedad clasificada que hemos considerado en el punto anterior de este estudio.

\section{LAS NUEVAS FORMAS DE COMUNICACIÓN ACARREAN NUEVAS FORMAS DE PARTICIPACIÓN Y CONTROL COMO EL RECALL}

Las nuevas tecnologías de comunicaciones electrónicas posibilitan un mundo de facultades insospechadas que generan muchas dudas pero ofrecen o pueden ofrecer también algunas soluciones nuevas a viejos problemas de forma probablemente más eficiente que las soluciones actualmente disponibles.

140 En este sentido señala Norberto Bobbio: «Huelga decir que el control público del poder es mucho más necesario en una edad como la nuestra, en que los instrumentos técnicos de los que puede disponer quien ostenta el poder para conocer capilarmente todo lo que hacen los ciudadanos, están enormemente aumentados, son prácticamente ilimitados. Si he mostrado algunas dudas respecto a que la computercracia pueda ser útil para la democracia gobernada, no tengo la menor duda acerca del servicio que puede prestar a la democracia gobernante. El ideal del poderoso ha sido siempre el de ver todos los gestos y escuchar todas las palabras de sus súbditos (posiblemente sin ser visto ni escuchado) ideal que, por supuesto, es hoy inalcanzable (en Internet, como medio de comunicación, el autor, que publicó su trabajo en 1985, no podría sostener tal afirmación en el momento presente, añadimos nosotros). Ningún déspota de la antigüedad, ningún monarca absolutista de la era moderna, aún rodeado de miles de espías, pudo obtener jamás sobre sus súbditos todas las informaciones que el más democrático de los gobiernos puede conseguir hoy gracias al empleo de los cerebros electrónicos». Norberto Bobbio, «El futuro de la democracia». Ed. Plaza \& Janés, 1985, pág. 36-37.

141 Greenwald, Glenn, «Snowden: Sin un lugar donde esconderse», Ediciones B, Barcelona, 2014. 
Si en las ciencias duras el stock de conocimientos y el stock de tecnología elevan los límites del bienestar humano, pero, de hecho, no determinan por si mismos la satisfacción humana que se alcanza dentro de esos límites, como recordara North ${ }^{142}$ ese deseable logro en lo que respecta a la participación política democrática depende, en amplia medida, de los programas y actividades políticas de los grupos en los que se divide o agrupan las modernas sociedades digitales y de la forma en que sean capaces de conjugar las opciones posibles con las ideologías en presencia. La participación, por ello, y la forma en la que esa participación se desarrolla es un factor de relevante importancia en las modernas sociedades democráticas. Por lo anterior el rediseño de las instituciones, su modificación cuando proceda y la imaginación primero y creación después de instituciones que se adapten mejor a las necesidades sociales, debe ser preocupación y tarea de la ciencia constitucional si lo que pretende es servir a valores superiores cuales son los consagrados en las propias constituciones, como en las pactos y convenios internacionales y universales de derechos humanos, en el marco que aquí consideramos de la participación ciudadana mediante nuevas adaptaciones para lograr democracias más responsables y que conciten, por ello, la adhesión a su desempeño de los ciudadanos en aquella vieja pero siempre actual expresión de Lincoln pronunciada en el discurso de Gettysburg de 1864 como gobierno del pueblo, por el pueblo y para el pueblo. Expresión tan sencilla de formular como compleja de articular en la práctica sin falsear la correcta intelección y coherencia de sus tres postulados y que conviene confrontar con otra expresión posiblemente del mismo autor pronunciada en Clinton cuando señalase ${ }^{143}$ que: Puedes engañar a todo el mundo algún tiempo, puedes engañar a algunos todo el tiempo, pero no puedes engañar a todo el mundo todo el tiempo, que, en una Democracia de opinión pública virtual electrónica quizá es el problema más importante que se le plantea a ésta. Tener pueblos instruidos y capaces, resilentes a la manipulación y a la demagogia en los que esos «algunos» no sean todos o casi todos todo el tiempo, lo que en la era de Internet, de la Sociedad de la Información y de las redes sociales ${ }^{144}$ con comunicaciones segmentadas y fácilmente polarizables ${ }^{145}$ es una circunstancia - como hemos señalado — sumamente preocupante por su real y actual posibilidad. Como demostró Walter Quattrociocchi ${ }^{146}$ en un estudio de 55 millones de internautas, los

142 North, Douglas C, «Estructura y cambio en la historia económica», Alianza, Madrid, 1994, pág. 31.

${ }_{143}$ Existen dudas acerca de si esta famosa cita fue pronunciada o no por el Presidente, se cita que Abraham Lincoln pudo pronunciarla en una convención en Clinton, Illinois el 2 de septiembre de 1858, durante un debate Lincoln-Douglas. Las evidencias disponibles se pueden rastrear desde 1901 en una obra titulada «Abe Lincoln's Yarns and Stories» compiladas por Alexander McClure, puede verse un Boletín de la Asociación Abraham Lincoln en:http://www.abrahamlincolnassociation.org/newsletters/7-3.pdf

${ }^{144}$ González de la Garza, Luis Miguel, «Redes sociales, instrumentos de participación democrática. Análisis de las tecnologías implicadas y nuevas tendencias», Dykinson, Madrid, 2015.

145 Sunstein, Cass R, «The Law ofGroup Polarization», en: Fishkin, James S y Peter Laslett, «Debating Deliberative Democracy», Blacwell Publishing, USA, 2003, págs. 80-102.

146 Quattrociocchi, Walter, «La era de la (des) información. La expansión de las redes digitales presenta un lado oscuro: la difusión masiva de informaciones falsas y teorías de la conspiración», Temas, Investigación \& Ciencia, primer trimestre, N. ${ }^{\circ}$ 91, 2018, págs.24-31 
usuarios están polarizados, se informan y forman su opinión según un proceso cognitivo que evita el conflicto, apoyando las narrativas que respaldan sus propias creencias. El principal motor de la difusión de contenidos es la homofilia: la tendencia a compartir información de usuarios que presentan un perfil similar al propio. Lo anterior conduce necesariamente a severos errores en la formación de la opinión pública de lo que se podrían denominar auténticas tribus virtuales como advierten Nyhan y $\operatorname{Reifler}^{147}$ lo que favorece extraordinariamente la difusión de fake news en masas de público polarizado, quizá esa es una de las razones que advirtiera Jonathan Swift en su célebre expresión por la que «la falsedad vuela y la verdad viene cojeando después de ella». Ya que las redes sociales virtuales replican la dinámica de las redes sociales no virtuales con la salvedad de que las primeras aceleran extraordinariamente la velocidad de circulación de la información en sociedades hiperconectadas.

Nuestras sociedades democráticas representativas y, por lo tanto, elitistas como hemos señalado sufren un distanciamiento, un hartazgo cada vez más acentuado y preocupante porque los ciudadanos no se sienten convenientemente representados en las instituciones lo que genera un preocupante espacio que puede ser ocupado por movimientos populistas orientados ala supresión del sistema democrático.

Instituciones como el «Recall ${ }^{148} »$ o la destitución y reelección de cargos públicos electos, con una milenaria tradición que puede rastrearse en sus primitivas formulaciones en Grecia con la institución del ostracismo ${ }^{149}$ y que fue uno de los rasgos más sobresalientes de la vida pública ateniense del siglo v como precisa Sinclair. ${ }^{150}$ Institución, el Recall pensada y querida por Emmanuel J. Sieyes ${ }^{151}$ para impedir la alienación del elector por el representante y que en la actualidad ha llegado a producirse jurídicamente tal temida alienación en virtud de la prohibición constitucional del mandato imperativo. Institución, por otra parte, que es jurídica-

147 Brendan Nyhan \& Jason Reifler «The roles of information deficits and identity threat in the prevalence of misperceptions», Journal of Elections, Public Opinion and Parties, 2018, pág 3.

${ }_{148}$ Cronin, Thomas E, «Direct Democracy. The Politics of Initiative, Referendum and Recall» Harvard University Press, 1989, págs, 125-157.

149 La ley del ostracismo en Atenas, data del año 510 a. C., fue impuesta por Clístenes y se puso en práctica en el año 487 a. C. como lucha contra la tiranía. Cada año el Demo, decidía en una reunión regular de la Asamblea en la sexta pritania, aproximadamente en enero, si se celebraba una ostrakophoria (votación de ostracismo). Si el resultado era afirmativo, la ostrakophoria señalada se celebraba en la octava pritánia. El ciudadano inscribía en un trozo de vasija rota (ostrakon) el nombre de la persona quien deseaba alejar de Atenas. Conseguido el quórum de 6000 personas, el individuo con mayor número de ostrakas contra él debía marcharse al exilio por diez años. Durante las reuniones no se permitía el debate. Sin embargo, el intervalo daba lugar a discusión entre los individuos; es opinable si tal decisión privada llevaría a decisiones más ecuánimes que el debate público en una asamblea. El que se exigieran dos reuniones, significaba que la decisión no se tomaba de forma atropellada. Sinclair, R.K, «Democracia y participación en Atenas», Alianza Editorial, Madrid, 1999, págs. 292

150 Sinclair, R.K, «Democracia y participación en Atenas», Alianza Editorial, Madrid, 1999, págs. 291-294.

151 Ver nota 37. 
mente congruente como sostuviera Leibholz con el moderno Estado de partidos de la democracia de masas, y opuesta al parlamentarismo representativo democrático-liberal $^{152}$. Siendo un instrumento que en la actualidad ${ }^{153}$ se emplea tanto en Europa ${ }^{154}$ como en los Estados Unidos ${ }^{155}$, en Canadá ${ }^{156}$ en Venezuela ${ }^{157}$ o en

152 Leibholz, Gerhard, Op Cit, pág. 112.

153 No haremos aquí referencia a la crítica hecha por Marx en sus comentarios a la Comuna de París al mandato libre, ni a las revocatorias de mandato que se incluyó en las sucesivas constituciones soviéticas.

154 Suiza, prevé la institución del Recall en seis cantones, en los que se exigen los siguientes números de firmas para su activación: Berna (30.000 firmas, que representan el $4 \%$ de los ciudadanos mayores de edad); Schaffhausen (1.000 firmas, $2 \%$ de los ciudadanos mayores de edad); Solothurn (6.000 firmas, $3 \%$ de los ciudadanos mayores de edad); Ticino (15.000 firmas, $7 \%$ de los ciudadanos mayores de edad); Thurgau (20.000 firmas, $13 \%$ de todos los ciudadanos mayores de edad) y Uri (600 firmas, $3 \%$ de los ciudadanos mayores de edad).

155 Recordemos que la institución del Recall apareció por primera vez en América colonial en las leyes del Tribunal General de la Colonia de la Bahía de Massachusetts en 1631. Con posterioridad y durante la revolución americana los Artículos de la Confederación de 7 de julio de 1778 estipularon que las legislaturas estatales podían destituir a los delegados del congreso continental, en su artículo V. En la actualidad en 19 Estados de los EE.UU., están regulados los procedimientos de Recall, estos son: Alaska - Const. Art. 11, § 8; AS §15.45.510-710, 15.60.010, 29.26.250-350. Arizona Const. Art. 8, §1-6; Ariz. Rev. Stat. §19-201 - 19-234. California - Const. Art. 2, §13-19; CA Código de Elecciones \$11000-11386. Colorado - Const. Art. 21; Colorado. Rev. Stat. \$1-12-101 - 1-12-122, 23-17-120.5, 31-4-501 - 31-4-505. Georgia - Const. Art. 2, § 2.4; Ga. Código §214-1 y siguientes. Idaho - Const. Art. 6, § 6; Código de Idaho §34-1701 - 34-1715. Illinois Const. Art. 3. § 7. Kansas - Const. Art. 4, § 3; KSA §25-4301 - 25 a 4331. Louisiana Const. Art. 10, §26; La. Estadísticas. Ana. § 18: 1300.1 - 18: 1300.17. Michigan — Const. Art. 2, $\S$ 8; Michigan. Ley de Elecciones $\$ 168.951$ - 168.975. Minnesota - Const. Art. 8, § 6; Minnesota. Stat. Ana. \$211C.01 y siguientes. Montana - Mont. Code § 2-16-601 - 2-16-635. Nevada Const. Art. 2, § 9; Nev. Rev. Stat. §294A.006, cap. 306, 539,163 a 539,183. Nueva Jersey Const. Art. 1, § 2 (b); NJ Rev. Stat. Ana. § 19: 27A-1 - 19: 27A-18. Dakota del Norte Const. Art. 3, § 1 y 10; Código siglo ND Ann. §16.1-01-09.1, 44-08-21. Oregon - Const. Art. 2, § 18; O. Rev. Stat. §249.865 - 249.880. Rhode Island - Const. Art. 4, § 1. Virginia - Virginia Código §24.2-233. Washington - Const. Art. 1 segundo. 33-34; Wash. Rev. Código §29A.56-110 y siguientes, y Wisconsin — Const. Art. 13, § 12; Wis. Stat. Ana. §9.10. Para ver los procedimientos puede verse: http://www.ncsl.org/research/elections-and-campaigns/recall-of-state-officials.aspx

156 En la asamblea legislativa de la Columbia Británica (Canadá) se encuentra prevista la facultad de hacer efectivo el Recall de los representantes elegidos.

157 Artículo 72. Todos los cargos y magistraturas de elección popular son revocables. Transcurrida la mitad del período para el cual fue elegido el funcionario o funcionaria, un número no menor del veinte por ciento de los electores o electoras inscritos en la correspondiente circunscripción podrá solicitar la convocatoria de un referendo para revocar su mandato. Cuando igual o mayor número de electores y electoras que eligieron al funcionario o funcionaria hubieren votado a favor de la revocatoria, siempre que haya concurrido al referendo un número de electores y electoras igual o superior al veinticinco por ciento de los electores y electoras inscritos, se considerará revocado su mandato y se procederá de inmediato a cubrir la falta absoluta conforme a lo dispuesto en esta Constitución y en la ley. La revocación del mandato para los cuerpos colegiados se realizará de acuerdo con lo que establezca la ley. Durante el período para el cual fue elegido el funcionario o funcionaria no podrá hacerse más de una solicitud de revocación de su mandato. Constitución de la República Bolivariana de Venezuela, Gaceta Oficial Extraordinaria N. 36.860 de 30 de diciembre de 1999.

N. ${ }^{\circ} 103$, septiembre-diciembre 2018, págs 257-302 
Filipinas ${ }^{158}$ encontrándose en la actualidad en el Reino Unido en vigor bajo la Recall of MPs Act 2015 de 26 de Marzo, patrocinada por Nick Clegg, The Deputy Prime Minister's Office. ${ }^{159}$ Diseñado sobre una nueva dimensión electrónica participativa puede ser un instrumento que conjuntamente con el sufragio electrónico «no secreto» y destinado o aplicado a éste y o a un conjunto de actividades o funciones tasadas o específicas de destitución y reelección como el ejercicio del Recall virtual, consideramos que podrían ser quizá instrumentos útiles y valiosos para revitalizar la democracia representativa de integración jurídicamente responsable en la fase de remoción de los representantes que incurran en conductas tasadas que justifiquen el proceso de revocación. Estas estrategias, son quizá piezas de un mecano jurídico que debe rearmarse y redefinirse constitucionalmente por parte de los partidos políticos que pueden ser considerados, parafraseando a D.H. Robertson como "islas de poder ideológico consciente en un océano de cooperación inconsciente» y por ello insustituibles, como advirtiera correctamente Gerhard Leibholz ${ }^{160}$ si bien, dentro de un nuevo marco evolutivo de menor poder y mayor control y residenciando más su actividad en la sociedad civil que debe ser base de su legitimidad como de su exigencia de responsabilidad y no de su inserción en el Estado como cuasi órganos que es, en lo que de facto, no de iure parece que se han venido transformando tras la segunda Guerra Mundial.

\section{LOS PARTIDOS POLÍTICOS HAN DETERIORADO LA CONFIANZA DE LOS CIUDADANOS EN LA DEMOCRACIA}

Recordemos con Bobbio ${ }^{161}$ que la concepción original de la democracia no tuvo en cuenta la existencia de los partidos políticos; al contrario, en una de las más firmes defensas de la democracia representativa, la del Federalista y en su número X escrito por Madison ${ }^{162}$ con algún precedente en Hume ${ }^{163}$ señalaba que uno de los beneficios de la democracia representativa respecto de la democracia directa estribaba, precisamente, en la mitigación de los efectos más perniciosos de las facciones, es decir, de

158 Código de Gobierno Local de 1991, RA 7160, Capítulo 5.

159 Puede consultarse en: http://www.legislation.gov.uk/ukpga/2015/25/contents/enacted/data. htm

${ }^{160}$ Gerhard Leibholz, «Representación e Identidad», en Teoría y sociología críticas de los partidos políticos, Kurt Lenk (ed. lit.), Franz Neumann (ed. lit.), Anagrama, 1980, págs. 205-277.

161 Bobbio, Norberto, «Teoría General de la Política», Trotta, Madrid, 2003, págs. 505-506.

162 Hamilton, A, J. Madison y J.Jay, «El Federalista», FCE, México, 1994, págs. 35-41.

163 Así y para este autor: Cuando los hombres militan en una facción, son capaces de olvidar, sin vergüenza ni remordimientos, los dictados del honor y la moral para servir a su partido, y, sin embargo, cuando forman bando en torno a un punto de derecho o un principio no hay ocasión en que demuestren mayor empeño y un sentido más decidido de la justicia y la equidad. Una misma disposición social de los humanos provoca esa aparente contradicción. Hume, David, «Ensayos Políticos, Tecnos, Madrid, 1994, pág. 22. 
los partidos porque el ciudadano, el átomo social, en su independencia e individualidad es puesto en contacto directamente y sin intermediarios con el órgano que detenta el sumo poder de tomar decisiones colectivas obligatorias para toda la sociedad. No obstante, Norberto Bobbio ${ }^{164}$ recuerda que la democracia representativa, que no podía avanzar sin el progresivo aumento de la participación electoral hasta el límite del sufragio universal, no solamente no eliminó a los partidos, sino que los hizo necesarios. El término "partidocracia» refleja la situación en la que quienes toman las decisiones en las actuales democracias representativas no son los representantes en su calidad de libres mandatarios de los electores, sino los partidos mediante la disciplina de un mandato imperativo de partido prohibido jurídicamente en España en el número 2 del artículo 67 la Constitución. Estos genuinos cuerpos intermedios contra los que conscientemente se luchaba finalmente han sido los que han heredado el sistema representativo democrático-liberal y hacen uso de él con relativa discrecionalidad en buena medida como genuinos rent seekers en la línea señalada por Tullock. ${ }^{165}$

Los modelos de democracia deliberativa, asociativa o consociativa chocan con el muro jurídico invisible para los no iniciados, para los ciudadanos no expertos, que es la independencia jurídica electores-representantes y la obviedad clara para los mismos ciudadanos de la dependencia, a su vez nítida y política entre los partidos y sus miembros representantes. Repensar los procedimientos de destitución de los representantes electoses una técnica posible y viable al servicio de una misma idea atemperar el poder de los partidos sobre sus miembros representantes. La confianza y la desconfianza como señala Bockenforde ${ }^{166}$ puede ser un buen ejemplo en el que articular el debate, y que se traduce en el recall en una limitación temporal del ejercicio del «cargo» que es una forma de control del poder y esa actividad de control es netamente jurídica. Los mecanismos técnicos o los procedimientos electrónicos pueden jugar un renovado papel al ser vectores no necesariamente únicos pero quizá sí suficientemente eficientes para articular los procesos previos de debate, reflexión pública, reunión de las firmas de destitución - lo que exige que el proceso no sea secreto y sea realizado mediante métodos de firma electrónica - todo ello rodeado de una regulación que determine los plazos, formas, modos, métodos y condiciones de ejercicio y que no requieren como hemos visto una extrema imaginación, sino adaptar los procedimientos ya existentes a las exigencias sentidas por cada comunidad política nacional con la finalidad de restaurar la confianza perdida o, al menos, intensamente erosionada por un sistema que, aun cuando necesario, su funcionamiento se ha apartado de las justificaciones que le dieron origen con una captura por los partidos politicos de los representantes y con escaso control y responsabilidad por parte de los electores que ha deteriorado gravemente el respeto y confianza por el procedimiento democrático.

164 Bobbio, Norberto, Op Cit, pág. 507.

165 Buchanan, Jmanes M y Gordon Tullock, «Derechos de propiedad y Democracia», Colegio de Economistas de Madrid-Celeste Ediciones, Madrid, 1995, págs. 137-146.

166 Bockenforde, Wolfgang, «Estudio sobre el Estado de derecho y la democracia», Trotta, Madrid, 2000, págs. 147-152. 
Lo que supone, en todo caso una relativización evidente de la normatividad de la Constitución como ya advirtiera Werner Kagi ${ }^{167}$ porque en el fondo los valores superiores y fundamentales que son la esencia del programa Constitucional quedan afectados por la pérdida de confianza de los ciudadanos en las instituciones participativas. Benjamín Constant ${ }^{168}$ no podía ser más preciso cuando advirtiera que cuando el pueblo cree en su Constitución mira a la misma como un todo indivisible y cuando los roces ocasionados por las faltas de ésta lo hieren, se aleja de ella en su totalidad. En vez de dirigir su descontento contra ciertas partes cuya mejora podría esperar, lo dirige contra el conjunto al que mira como incorregible y transforma en terreno propicio para el surgimiento de los populismos agresivos que encuentren en los nuevos medios electrónicos una ecología de nuevos instrumentos técnicos verdaderamente eficientes y aptos para su propagación y desarrollo en la sociedad virtual de la información.

La intensa fragmentación de la opinión pública que las nuevas tecnologías están propiciando, las nuevas formas de populismo que esa fragmentación impulsa para la obtención del poder político exigen hoy tal vez más que nunca una reforma en los partidos políticos que advierta de su papel central de vertebradores de las corrientes de pensamiento y opinión políticas, en vez de que las fuentes de polarización de la opinión externas o internas que crecen al calor de las nuevas tecnologías brevemente examinadas supriman esa capacidad de vertebración necesaria en las democracias representativas. Comprender las tecnologías implicadas es esencial para poder regularlas adecuadamente por ello la interacción Ciencia y Derecho es cada vez más crucial en un mundo donde la tecnología — impulsada por poderes privados - genera una forma de legalidad fáctica, como advirtiera correctamente Lawrence Lessig ${ }^{169}$ capaz de generar distorsiones sociales cada vez más profundas y rápidas que el Derecho tiene como vocación prevenir. Podemos pensar en los algoritmos que gobiernan el procesamiento matemático de la información como señala Cathy $\mathrm{O}^{\prime} \mathrm{Neill}{ }^{170} \mathrm{como}$ un exponente de esa legalidad fáctica, los modelos matemáticos a pesar de su reputación de imparcialidad, reflejan objetivos e ideologías que deben ser objeto de escrutinio público mediante el levantamiento del velo del secreto empresarial cuando éstos puedan tener incidencia razonable en los procedimientos democráticos y ser, en esos casos, accesibles al público, evaluables y transparentes. La tecnología de la información se diseña, no se descubre, por ello los algoritmos deben diseñarse para evitar sesgos negativos humanos, no para ignorarlos y, en el peor de los casos explotarlos. Principios éticos mínimos como los que se proponen para el uso de la IA, tales como los establecidos en la conferencia de ASILOMAR ${ }^{171}$ de 2017 deberían también exten-

167 Kagi, Werner, «La Constitución como ordenamiento jurídico fundamental del Estado», Dykinson, Madrid, 2005, págs. 54-72.

168 Constant, Benjamin, «Principios de política aplicable a todos los gobiernos» Capítulo III, Condiciones necesarias para que las Constituciones no sean violadas, Katz, Madrid, 2010, pág. 116.

169 Lessig, Lawrence, «The Code version 2.0», Cambridge, Basic Books, 2006.

170 O`Neill, Cathy, «Armas de destrucción matemática», Capitán Swing, Madrid, 2017, pag.31.

171 https://futureoflife.org/ai-principles/ (último acceso, 8 de septiembre 2018) 
derse a los algoritmos que hagan uso de la IA o no. Se puede pensar en el Derecho a la intervención humana establecido en el artículo 22 del Reglamento 2016/679 del Parlamento Europeo y del Consejo de 27 de abril de 2016 en lo que respecta a tratamientos automatizados —algorítmicos - y a no ser objeto de una decisión basada únicamente en ese tratamiento automatizado, incluida la elaboración de perfiles.

Title.

The crisis of representation: the new political relations between democracy, populism, private powers and technocracy in the era of the information society.

\section{Summary:}

1. A democracy of excessively discontinuous exercise 2. The new media as mirrors where formal democracy reflects. 2.1 Direct democracy and representative democracy, the insufficiency of an unveiled fiction. 2.2. Citizens in advanced democracy wish to participate. 2.3. From a class society to a classified society, the role of big data, 2.3.1. The psychometric profiles, 2.3.2. Electoral cognitive advertising and microtargeting. 2.4 Powers private public powers. 3 . The new forms of communication include new ways of participation and control as the recall. 4. Political parties have deteriorated the confidence of citizens in democracy.

\section{Resumen:}

El trabajo que presentamos trata de contemplar como la erosión del sistema representativo de partidos políticos ha deteriorado gravemente la confianza de los ciudadanos en su efectividad y responsabilidad, hasta el extremo de que nuevos movimientos sociales y políticos propugnen retornar a modelos de democracia directa. Defendemos aquí que ello no es posible, ni deseable precisamente en un momento en el que los nuevos medios técnicos hacen más posible que nunca la aparición de populismos articulados sobre bases tecnológicas que son de una extraordinario peligro para las democracias del siglo XXI.

Para ello estudiamos algunas de las ideas centrales de la democracia representativa y de la democracia directa, poniéndolas en conexión con el poder que las nuevas tecnologías como el Big Data, la propaganda cognitiva electoral y otras técnicas de comunicación electrónica virtual están desplegando sobre nuestras modernas democracias de opinión. Tratamos de poner en evidencia algunos de sus riesgos más relevantes sugiriendo, 
también, algunos instrumentos para mejorar la siempre perfectible tanto como necesaria democracia representativa, basada en partidos políticos más responsables donde el mandato imperativo de partido sea atemperado por instituciones como el Recall de cada vez mayor uso en el marco del Derecho Constitucional comparado. Aspectos como el rediseño de la privacidad forman parte, brevemente, de la investigación ya que en una ecología de nuevos medios técnicos de procesamiento de la información sólo una intensificación normativa del respeto de la privacidad puede ser la única estrategia de contención de un futuro que sin ella afectaría gravemente a la dignidad humana.

\begin{abstract}
:
The work that we present tries to contemplate how the erosion of the representative system of political parties has seriously deteriorated the confidence of the citizens in their effectiveness and responsibility, to the extent that new social and political movements propose to return to models of direct democracy. We argue here that this is neither possible nor desirable at a time when the new technical means make more possible than ever the emergence of populisms articulated on technological bases that are an extraordinary danger for the democracies of the 21st century.

To this end, we study some of the central ideas of representative democracy and direct democracy, linking them to the power that new technologies such as Big Data, electoral cognitive propaganda and other virtual electronic communication techniques are deploying on our modern democracies of opinion. We try to highlight some of its most relevant risks, suggesting also some instruments to improve the always perfectible as much as necessary representative democracy based on more responsible political parties where the imperative party mandate is tempered by institutions like the Recall at a time greater use within the framework of comparative Constitutional Law. Aspects such as the redesign of privacy are briefly part of the research since in an ecology of new technical means of information processing, only a normative intensification of respect for privacy may be the only strategy to contain a future that without It would seriously affect human dignity.
\end{abstract}

\title{
Palabras clave:
}

Democracia, representación; Internet; Big Data; elecciones; propaganda cognitiva, perfiles psicométricos, Recall, participación política, comunicación pública, privacidad.

\section{Key words:}

Democracy, representation; Internet; Big Data; elections; Cognitive propaganda, psychometric profiles, Recall, political participation, public communication, privacy. 